\title{
Numerical parametric study on behavior of bearing reinforcement earth walls with different backfill material properties
}

\author{
K. Sukmak ${ }^{1}$, J. $\operatorname{Han}^{2}$, P. Sukmak ${ }^{3}$ and S. Horpibulsuk ${ }^{4}$ \\ ${ }^{1}$ PhD Graduate, School of Civil Engineering, Suranaree University of Technology, 111 University Avenue, \\ Muang District, Nakhon Ratchasima 30000,Thailand, E-mail: k.sukmak_ce@hotmail.com \\ ${ }^{2}$ Professor, The University of Kansas, CEAE Department, 2150 Learned Hall, $1530 \mathrm{~W}$. 15th Street, \\ Lawrence, Kansas 66405,USA, E-mail: jiehan@ku.edu \\ ${ }^{3}$ Professor, School of Engineering and Resources, Walailak University, 222 Thaiburi, Thasala District, \\ Nakhonsithammarat80161, Thailand, E-mail: patimapon.su@wu.ac.th \\ ${ }^{4}$ Professor and Chair, School of Civil Engineering, and Director, Center of Excellence in Innovation for \\ Sustainable Infrastructure Development, Suranaree University of Technology, 111 University Avenue, \\ Muang District, Nakhon Ratchasima 30000, Thailand, E-mail: suksun@g.sut.ac.th (corresponding author)
}

Received 10 December 2015, revised 13 March 2016, accepted 11 April 2016, published 31 May 2016

\begin{abstract}
This paper presents a numerical parametric study on behavior of bearing reinforcement earth (BRE) walls with different backfill properties using the finite-element method software PLAXIS 2D. The primary objective of this study was to improve the understanding of bearing stress, settlement, lateral earth pressure, and horizontal wall movement of BRE walls with different backfill materials. The second objective of this study was to evaluate the effects of various soil-structure interactions, foundations, and stiffness of reinforcements on horizontal wall deformations. The backfill materials consisted of four types of soil, which were mixtures of silty clay and sand at different fine contents of $2,20,40$, and $80 \%$ by dry weight. The model parameters for the numerical simulation were obtained from the conventional laboratory tests and back-calculated from the laboratory pullout tests of the bearing reinforcement. The geotextile elements were used to model the bearing reinforcements by converting the contribution of friction and bearing resistances to the equivalent friction resistance, which was represented by the soil-bearing reinforcement interaction ratio, $R_{\text {inter }}$. The values of $R_{\text {inter }}$ decreased following a polynomial function as an increase of fine content in the ranges of $0.65-0.38$ and $0.75-0.40$ for the numbers of transverse members, $n=2$ and 3, respectively. The simulated bearing stress in the reinforced zone decreased from the front to the back of the wall because the BRE wall behaved as a rigid body built on the relatively firm foundation retaining the unreinforced backfill. The foundation settlement decreased from the facing of the wall to the unreinforced zone for all backfill properties due to the slight rotation of the wall. The relationship between the maximum horizontal wall movement and the fine content can be expressed by a polynomial function. The maximum horizontal wall movement significantly increased as the fine content increased. The excessive movement was realized when the fine content was greater than $45 \%$. The increase of the fine content moved the location of the maximum wall movement higher up from the mid to the top of the wall. A numerical parametric study was conducted to investigate the soil-structure interaction, foundation, and stiffness of reinforcement. These parameters affected the horizontal wall deformation, which is especially important for serviceability of BRE walls. The knowledge gained from this study provides a preliminary guideline in predicting the behavior of BRE walls and may be used to investigate other BRE walls with different wall heights and features of bearing reinforcements.
\end{abstract}

KEYWORDS: Geosynthetics, Bearing reinforcement, Fine content, Finite-element analysis, Mechanically stabilized earth wall

REFERENCE: Sukmak, K., Han, J., Sukmak, P. and Horpibulsuk, S. (2016). Numerical parametric study on behavior of bearing reinforcement earth walls with different backfill material properties. Geosynthetics International, 23, No. 6, 435-451. [http://dx.doi.org/10.1680/jgein.16.00008]

\section{INTRODUCTION}

Mechanically stabilized earth (MSE) walls are one type of earth retaining structures. The concept of MSE walls was pioneered by Henri Vidal of France in the 1960s and they are also referred to as 'reinforced earth or reinforced soil structure'. Over the past three decades, the use of MSE structures in civil engineering applications has grown 
rapidly worldwide (including Thailand, China, Australia, Canada, Japan, and the United States of America) because there are several benefits, such as cost-effective and simple construction techniques compared with conventional gravity retaining walls (Bathurst 1993; Miyata et al. 2011; Esfandiari and Selamat 2012; Leshchinsky et al. 2012; Dash and Bora 2013; Suksiripattanapong et al. 2013; Naeini and Gholampoor 2014; Riccio et al. 2014; Biabani and Indraratna 2015; Han 2015; Yu et al. 2015).

An MSE wall is a composite mass formed by the combination of backfill and metallic or geosynthetic reinforcements (i.e. steel strips, geogrid, and geotextile), which are able to sustain significant tensile loads. Coarse-grained soil is often required as a backfill material. When coarsegrained soils are not locally available within a construction site, the construction cost is largely dependent on haulage cost. The haulage cost between a borrow source and the construction site is often exorbitant. A potential means to reduce the construction cost is to use locally available soils as backfill materials. The use of locally available marginal soils (e.g. low-quality soils with more than $15 \%$ fine content) as a backfill could reduce the cost of fill material by as much as $60 \%$ in comparison with the use of high-quality offsite soils and reduce the air pollution from the transportation (Keller 1995; Esmaili et al. 2014). However, due to the low shear strength of fine-grained soil, internal stability against pullout failure is questionable. To increase the interface strength, Horpibulsuk and Niramitkornburee (2010) and Horpibulsuk et al. (2011) proposed the use of bearing reinforcement. Figure 1 shows the typical configuration of the bearing reinforcement, which is composed of a longitudinal member and transverse (bearing) members. The MSE wall reinforced by bearing reinforcement was designated as the bearing reinforcement earth (BRE) wall by Horpibulsuk et al. (2011). Similarly, Abdelouhab et al. (2011) have developed geosynthetic straps, which have high interface strength. The pullout resistance of the geosynthetic straps embedded in coarse-grained soils was also investigated.

MSE walls are often designed based on internal and external stability analyses to assess the system stability in term of factors of safety (FS). For internal stability, reinforcement should be designed against potential rupture and pullout. The pullout resistance of the reinforcement depends on the geometry and properties of the reinforcement and the soil properties and is often determined by pullout tests. The major limitation of this conventional design is that it is not possible to calculate lateral deformation, settlement, and soil stress distribution in MSE walls (Ho and Rowe 1994; Rowe and Ho 1998; Han and Leshchinsky 2004).

Horpibulsuk and Niramitkornburee (2010), Horpibulsuk et al. (2011) and Suksiripattanapong et al. (2012) conducted laboratory pullout tests of bearing reinforcement, full-scale tests, and two-dimensional (2D) numerical analysis of BRE walls, respectively. Their studies have addressed some important issues of BRE walls; however, most of their studies have been focused on coarse-grained (cohesionless) soils.

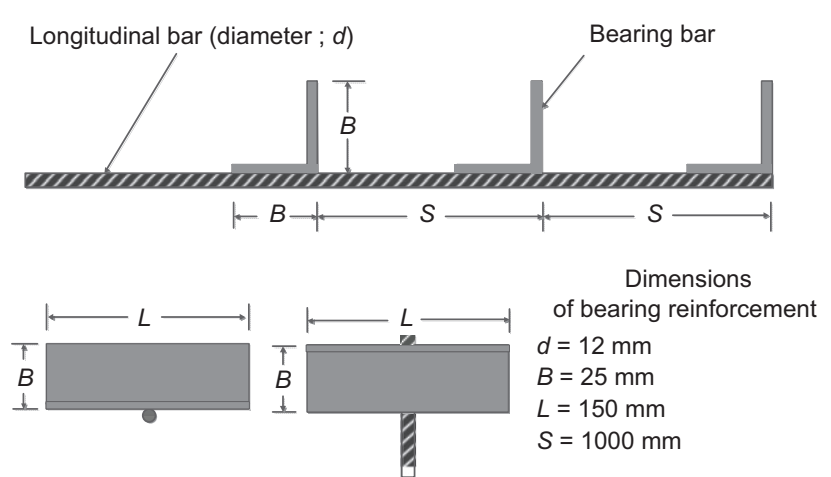

(a)

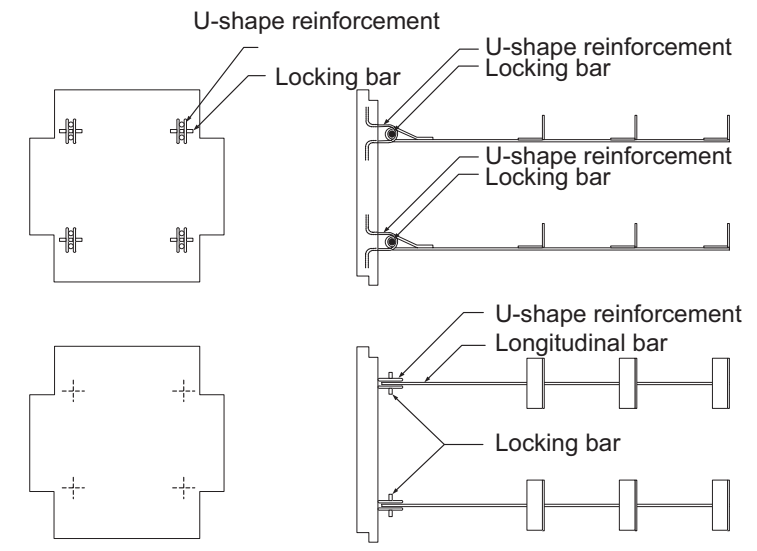

(b)

Figure 1. (a) Typical configuration of the bearing reinforcement. (b) Connection of the bearing reinforcement to wall facing

To investigate the use of fine-grained soil as a backfill material, Sukmak et al. (2015) and Sukmak et al. (2016) investigated the pullout mechanisms of the bearing reinforcements embedded in cohesive-frictional soils at various fine and water contents. The bearing pullout mechanism was found to be dominated by the fine content and the failure approached punching shear when the fine content was increased. However, this investigation was limited to large-scale pullout tests in the laboratory. It would be ideal if a full-scale BRE wall filled with cohesive-frictional soil could be constructed to investigate the actual behavior of an MSE wall, but construction cost and time are prohibitive. Hence, model simulation by using a numerical analysis can be an alternative method to investigate the behavior of BRE walls.

According to many researchers (Ho and Rowe 1994; Youwai and Bergado 2004; Bergado and Teerawattanasuk 2008; Reddy and Navarrete 2008; Abdelouhab et al. 2011; Suksiripattanapong et al. 2012; Abdi and Zandieh 2014; Golam et al. 2014; Wang et al. 2014; Damians et al. 2015; Hegde and Sitharam 2015), numerical methods (i.e. finite-difference and finite-element methods) have been widely used for design and analysis of MSE structures. Numerical methods can model structural components, material properties, construction sequence and compute deformations, forces, strains, and stress distribution at any location of interest in a reinforced soil structure (Mohamed et al. 2014). In addition, they can be used for 
design, parametric studies, and simulation of the behavior of the earth structures (Collin 1986).

However, the suitability of a numerical method for modeling MSE structures requires calibration and validation between calculated and observed behavior of laboratory and full-scale tests in order to produce convincing results. Hence, a numerical method validated with experimental test results should be used to investigate the behavior and performance of MSE structures. The PLAXIS program has been proved to be a powerful and accurate tool to predict the performance of the MSE wall and pullout test results (Bergado et al. 2003; Khedkar and Mandal 2009; Suksiripattanapong et al. 2012). Thus, the finite-element code incorporated in PLAXIS 2D was used in the present study.

In this study, finite-element models (FEMs) with material properties were first calibrated according to laboratory large-scale pullout tests reported by Horpibulsuk and Niramitkornburee (2010) and Sukmak et al. (2015) and the full-scale bearing reinforced earth wall reported by Horpibulsuk et al. (2011). The input material properties were obtained from direct shear tests with a box that was $30 \mathrm{~cm}$ in diameter to avoid the scale effect from conventional triaxial tests as the studied soils contain relatively large particles in comparison with the size of the conventional triaxial sample (Kim et al. 2005). The interface parameters between reinforcement and soil were obtained from laboratory large pullout tests reported by Horpibulsuk and Niramitkornburee (2010) and Sukmak et al. (2015) and the full-scale test results on a BRE wall were reported by Horpibulsuk et al. (2011). The calibrated models were then adopted in this study to investigate the behavior and performance of BRE walls with different backfill material properties.

The primary objective of this study was to improve the understanding of bearing stress, settlement, lateral earth pressure, and horizontal wall movement of BRE walls with different backfill materials during and at the end of construction. Horizontal wall deformations are especially important for serviceability of MSE structures. They can be induced by the deformations in reinforced and unreinforced zones, due to foundation lateral movement and settlement, and post-construction deformation. The post-construction deformation of the earth wall is mainly contributed by creep of the reinforcement, which is usually taken into account in a wall design. The creep of the reinforcement is usually assumed to result in a decrease in stiffness of reinforcement (Rowe and Ho 1998). Therefore, the deformation of the wall due to post-construction can be assessed by examining the effect of reducing the reinforcement stiffness.

The second objective of this study was to evaluate the effects of various soil-structure interactions, foundations, and stiffness of reinforcements on horizontal wall deformations. This objective was achieved by a parametric study. The knowledge gained from this study provides useful information for further analysis and design of other BRE walls with different types of backfills, ground conditions, and features of bearing reinforcement.
In this numerical study, the calibrated BRE wall model was used as a reference MSE structure for parametric investigations. A simplified method was introduced to model the bearing reinforcement by converting the contribution of friction and bearing resistance to the equivalent friction resistance (Suksiripattanapong et al. 2012). The equivalent friction resistance is represented by a soil-structure interaction factor $\left(R_{\text {inter }}\right)$, which was obtained by the back-analysis of the laboratory pullout test results. The relationship between the soil-structure interaction factor and the fine content was investigated. Fine is defined as the particles passing No. 200 US sieve size. The other model parameters used in this study were obtained from conventional laboratory tests.

Even though this simplified method of analysis of the BRE wall is similar to the previous research but the

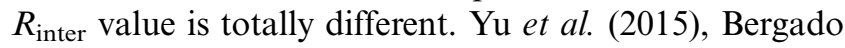
et al. (2000), Bergado et al. (2003) and Khedkar and Mandal (2009) showed that the $R_{\text {inter values of strip rein- }}$ forcement, and hexagonal reinforcement, and geocell are only $0.3,0.3-0.5$ and $0.1-0.3$, respectively, which are much lower than those of bearing reinforcement (typically in the range of 0.6 to 0.9 ) (Suksiripattanapong et al. 2016). The higher $R_{\text {inter }}$ come from the contribution by transverse members. As such, the previous studies, even with a similar method, are valid only at a particular range of $R_{\text {inter }}$ values and thus cannot address the behavior of BRE walls.

\section{FULL-SCALE TEST OF EARTH WALL FOR REFERENCE NUMERICAL MODEL}

\subsection{Foundation and backfill}

The construction of a BRE wall was completed on the campus of the Suranaree University of Technology (SUT) in Thailand on 20 July 2009. The foundation consisted of a $1.5 \mathrm{~m}$ thick weathered crust layer of silty sand, which was underlain by a medium dense silty sand layer down to about $6 \mathrm{~m}$ deep and then a very dense silty sand layer. Soil samples were obtained from a borehole at the construction site down to $8 \mathrm{~m}$ deep. The ground water was not detected during boring. The backfill for the earth wall was clean sand, which is classified as poorly graded sand (SP), according to the Unified Soil Classification System (USCS). The details of the foundation and the backfill can be found in Horpibulsuk et al. (2011).

\subsection{Construction and instrumentation of the test wall}

The test wall was $6 \mathrm{~m}$ high, $9 \mathrm{~m}$ wide, $6 \mathrm{~m}$ long at the top, and $21 \mathrm{~m}$ wide at the base, as illustrated in Figure 2. The side and back slopes were $1: 1$. The wall facing panels, which were made of segmental concrete panels $(1.50 \times 1.50 \times 0.14 \mathrm{~m})$, were placed on a lean concrete leveling pad $(0.15 \mathrm{~m}$ wide and $0.15 \mathrm{~m}$ thick $)$ two days after curing. During the construction, four facing panels were installed in the middle portion of the wall width $(9 \mathrm{~m} \times 6 \mathrm{~m} \times 6 \mathrm{~m})$ with eight reinforcement levels. The longitudinal reinforcement members for all layers were 


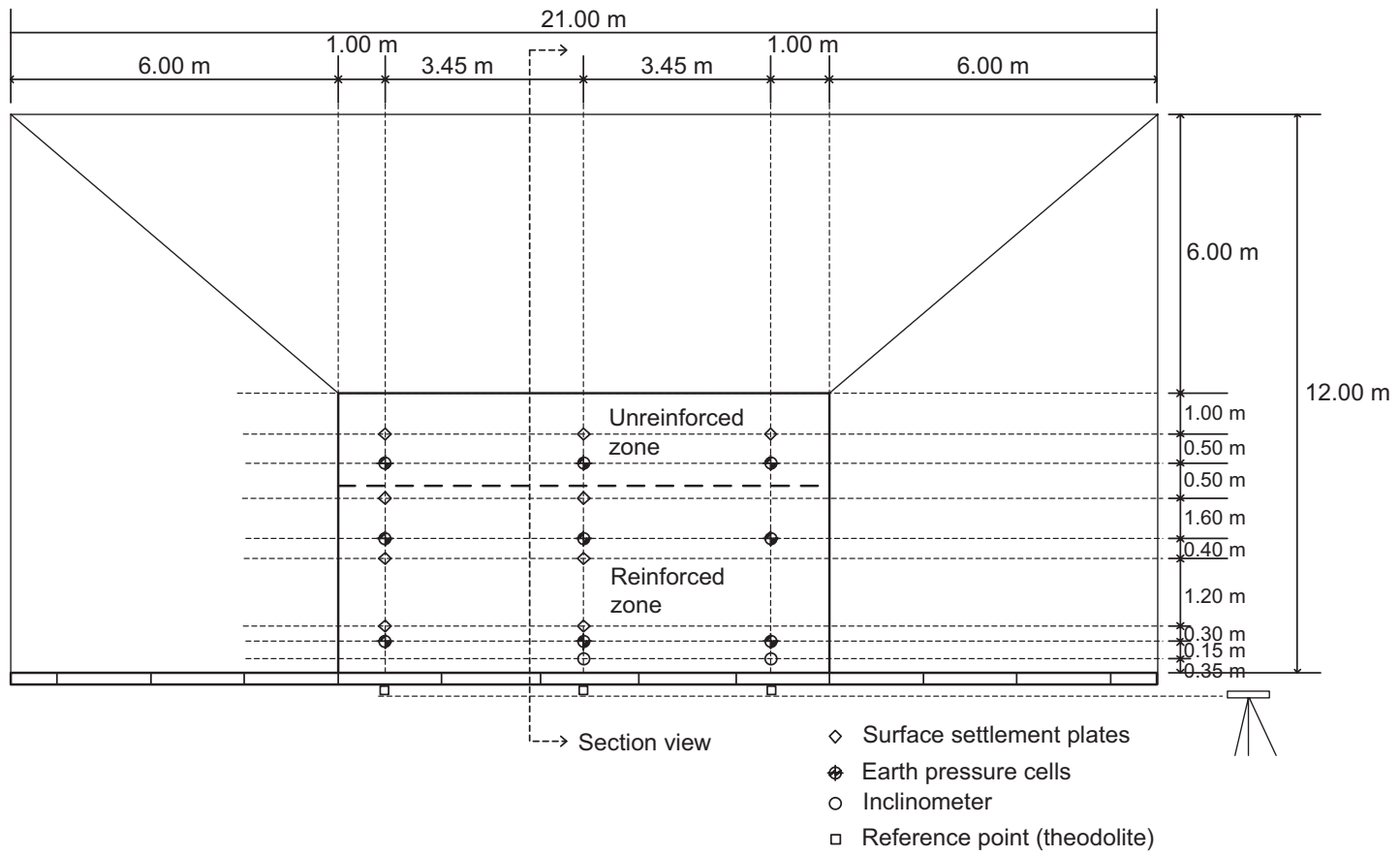

(a)

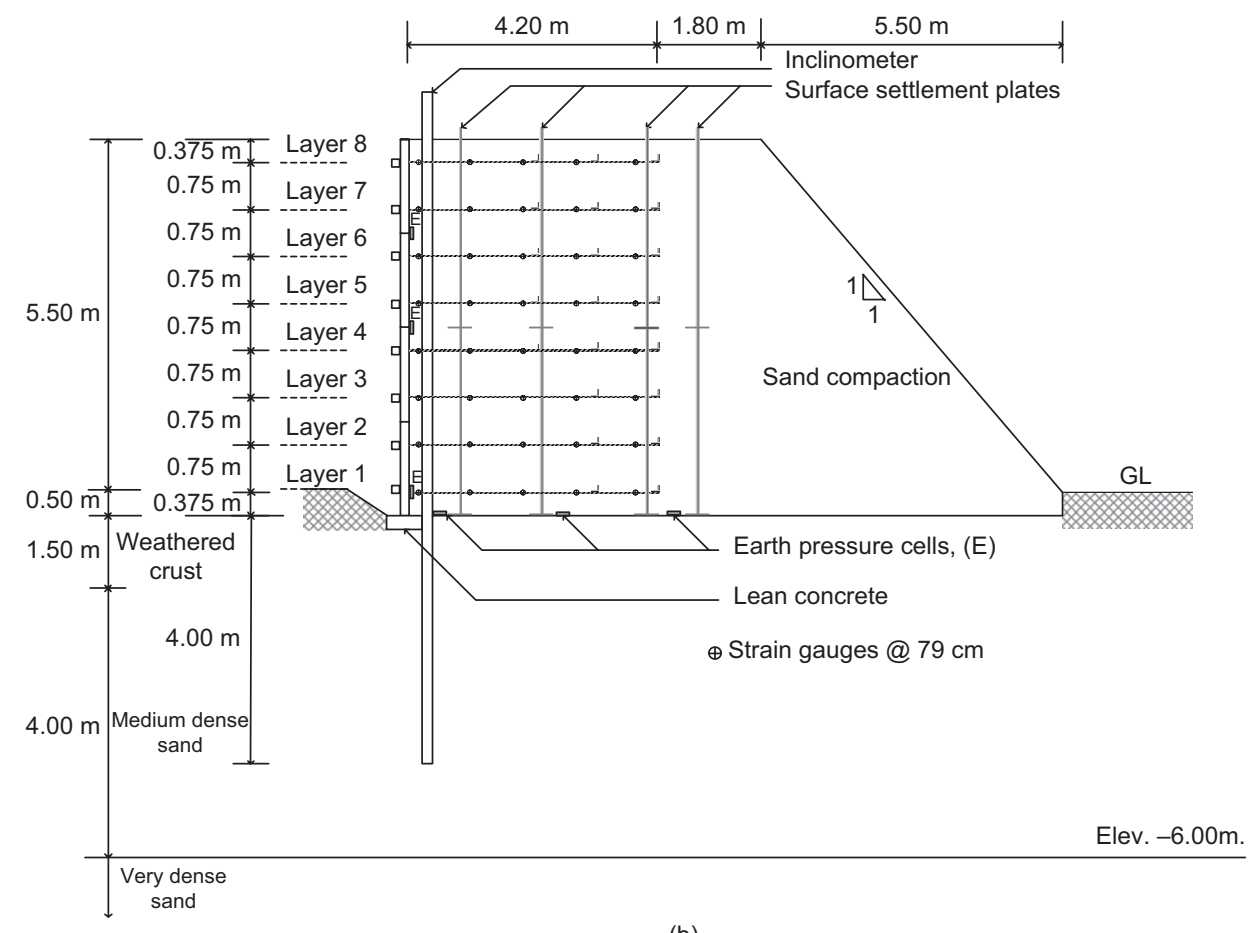

(b)

Figure 2. Schematic diagram of the test wall instrumentation: (a) plan view (b) section view

$12 \mathrm{~mm}$ diameter and $4.2 \mathrm{~m}$ long. The transverse members were equal steel angles that had $25 \mathrm{~mm}$ leg length $(B)$ and $180 \mathrm{~mm}$ length $(L)$. The transverse members were spaced at $750 \mathrm{~mm}$ for all transverse members. The vertical spacing between each reinforcement level was $750 \mathrm{~mm}$. Their horizontal spacing was $750 \mathrm{~mm}$ for levels 4-8 and $0.5 \mathrm{~m}$ for levels $1-3$. The details of the bearing reinforcement for each layer are summarized in Table 1.

The backfill was compacted in layers of about $0.15 \mathrm{~m}$ lift thickness to a density of greater than $90 \%$ of the standard Proctor maximum density. The total time spent for the construction of the wall was 20 days. The construction sequence is shown in Figure 3.

The BRE wall was extensively instrumented both in the subsoil and within the wall itself as shown in Figure 2. The ground water table observation well and piezometer were not used in this investigation because the ground water was deeper than $8 \mathrm{~m}$ (i.e. the bottom of boring). Lateral movement of each segmental panel during construction was recorded by a theodolite with reference to the benchmark. The lateral movements after the end of construction were measured using digital inclinometers. 
The inclinometer casing was installed from the top of the wall down to the medium dense sand about $4 \mathrm{~m}$ below the wall base. The earth pressure cells were installed behind the facing panels and on the subsoil. The settlement plates were installed in the subsoil foundation and the backfill.

Table 1. Reinforcement details for the test wall (Horpibulsuk and Niramitkornburee 2010)

\begin{tabular}{|l|l|c|c|}
\hline $\begin{array}{l}\text { Facing } \\
\text { panel }\end{array}$ & $\begin{array}{l}\text { Reinforcement } \\
\text { layer }\end{array}$ & $\begin{array}{c}\text { Spacing between } \\
\text { longitudinal members }(\mathrm{mm})\end{array}$ & Number \\
\hline 1 & 1 (bottom) & 500 & 2 \\
& 2 & 500 & 2 \\
2 & 3 & 500 & 2 \\
& 4 & 750 & 3 \\
3 & 5 & 750 & 3 \\
& 6 & 750 & 3 \\
4 & 7 & 750 & 3 \\
& 8 (Top) & 750 & 3 \\
\hline
\end{tabular}

\section{MATERIAL CONSTITUTIVE MODELS AND PARAMETERS}

The 2D Plaxis finite-element (FE) program was used to simulate the construction of the wall. The BRE wall was molded as a plane strain problem. The FE mesh and boundary condition are shown in Figure 4 . The nodal points at the bottom boundary were fixed in both directions and those on the side boundaries were fixed only in the horizontal direction. The soil elements were modeled using 15-noded triangular elements (totally 28631 nodes of 3190 elements). The local element size factor, which controls the mesh coarseness around the geometry line, of the wall facing and reinforcements was 0.1 and soil-reinforcement thickness factor was 0.05 . The simulation was performed under a drained condition because the ground water was not detected during the test. The properties of the compacted soil were determined from conventional laboratory tests that did not consider

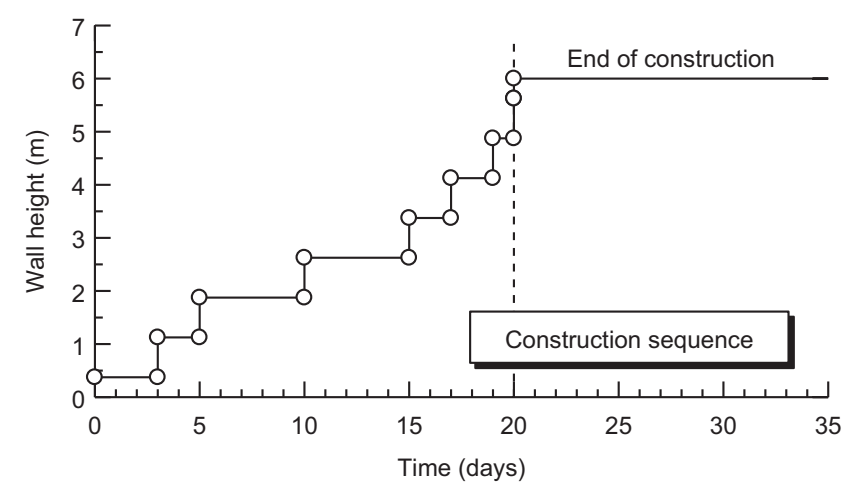

(a)
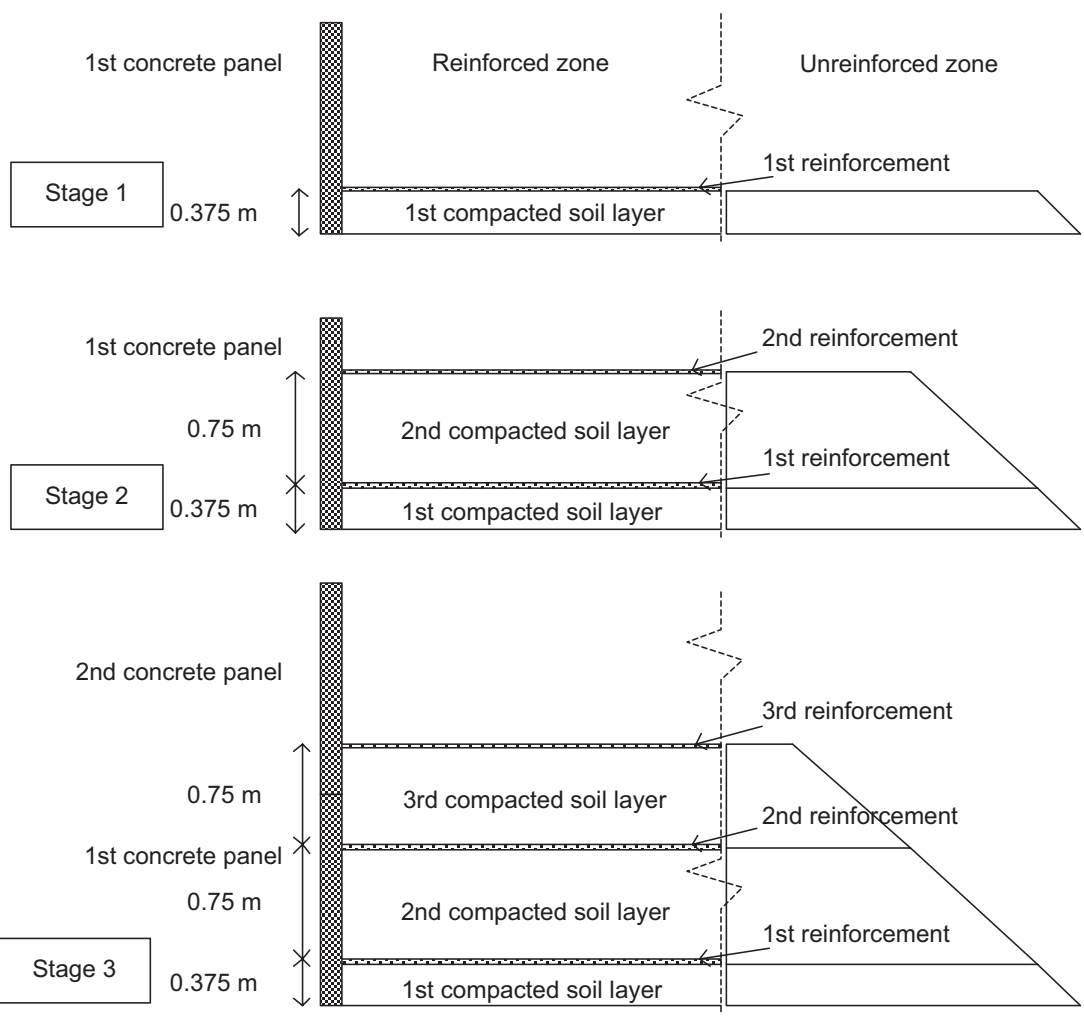

(b)

Figure 3. (a) Construction sequence. (b) Stage construction procedure (Stages 1-3) 


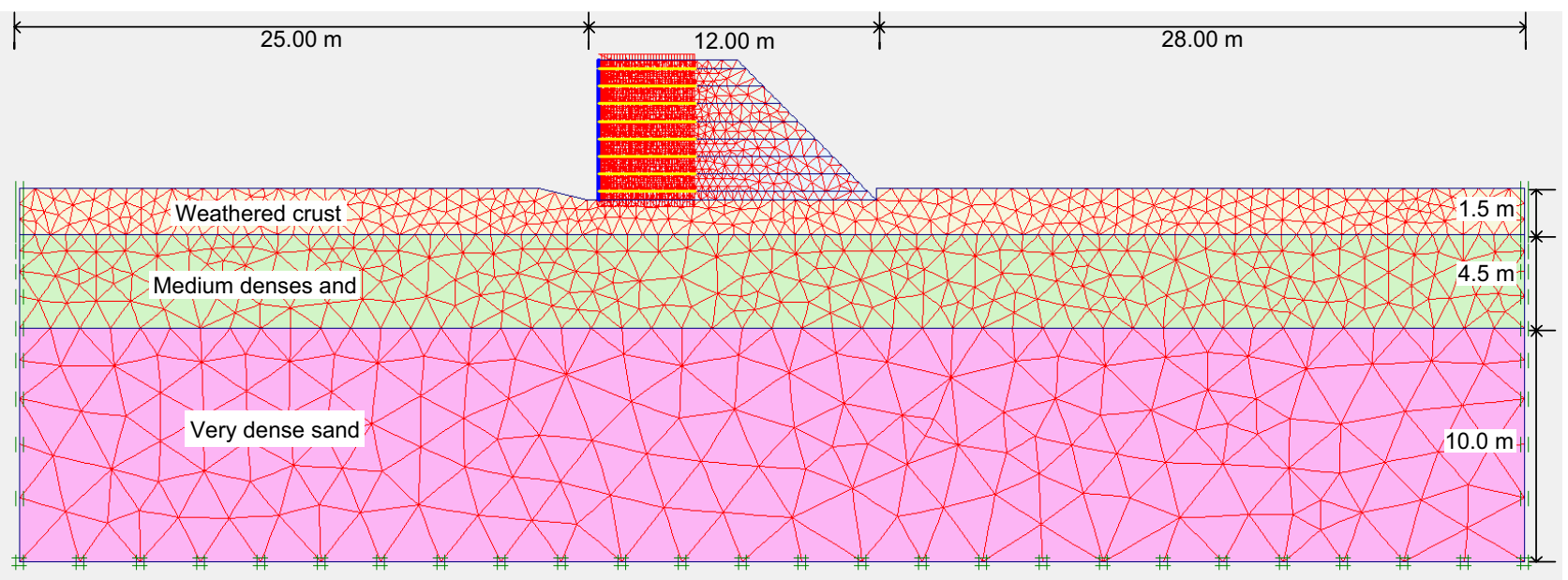

Figure 4. Numerical model and mesh details for $2 \mathrm{D}$ finite-element model simulation of BRE wall

the time-dependent behavior, such as creep of soil. The creep model was beyond the scope of this study because it aimed to simulate the wall behavior with simple and well-known soil models for practical design.

\subsection{Backfill and foundation}

\subsubsection{Backfill}

The backfill materials used in this study consisted of four types of soils, which were mixtures of silty clay and sand at different fine contents. The grain size distribution curves of the samples are shown in Figure 5. The four backfill materials were poorly graded sand $(\mathrm{F}: \mathrm{S}=2: 98)$, clayey sand $(F: S=20: 80)$, clayey sand $(F: S=40: 60)$, and high-plasticity clay $(\mathrm{F}: \mathrm{S}=80: 20)$, in which $\mathrm{F}$ stands for the percentage of fines and $\mathrm{S}$ stands for the percentage of sand. Considering the average normal stress at the mid-height of the backfill ( $3 \mathrm{~m}$ high), the average normal stress was calculated to be about $60 \mathrm{kPa}$, which was used to select the backfill properties of the BRE wall. The material properties used for simulation were determined according to the laboratory large-scale direct shear tests reported by Horpibulsuk and Niramitkornburee (2010) and Sukmak et al. (2015). This research aimed to use simple rational soil models with few parameters, which can be easily obtained from laboratory to compare the behavior of BRE walls with different fill materials. Considering the high stiffness of the bearing reinforcement and the high modulus of the compacted unsaturated soil, the soil movement was minimal and could be represented by a linear relationship. As such, all backfill materials were modeled as linearly elastic-perfectly plastic materials with the Mohr-Coulomb (MC) failure criteria, which had five input parameters: elasticity modulus $(E)$, Poisson's ratio $(v)$, cohesion $(c)$, internal friction angle $(\phi)$, and dilatancy angle $(\psi)$.

The apparent cohesion and the friction angle were determined using a large direct shear apparatus with a diameter of $350 \mathrm{~mm}$. The soil samples were prepared at the optimum water content (obtained from laboratory compaction tests) and transferred to the large direct shear box. For poorly graded sand $(\mathrm{F}: \mathrm{S}=2: 98)$, the apparent

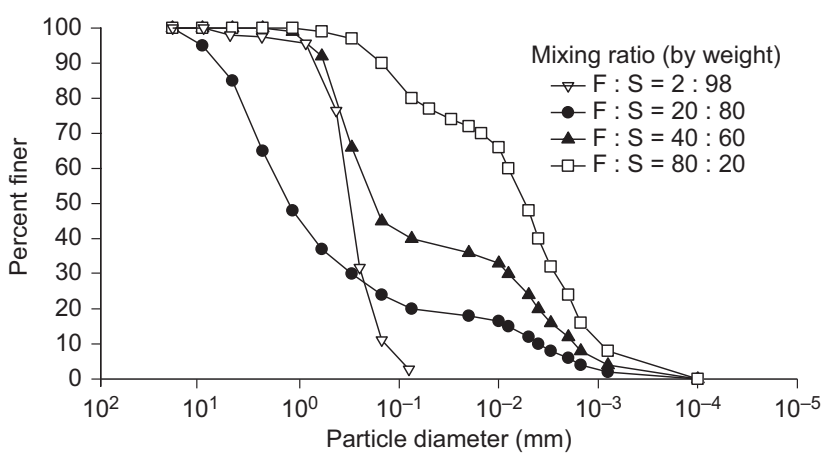

Figure 5. Grain size distributions

cohesion and the friction angle were determined under a drained condition and equal to $c^{\prime}=3 \mathrm{kPa}$ and $\phi^{\prime}=40^{\circ}$. However, for clayey sands and high-plasticity clay, the test commenced with no time allowed for the sample to consolidate during the applied normal stress and shearing. The shear force was then applied at a constant shearing rate of $1 \mathrm{~mm} / \mathrm{min}$ until the sample was sheared to $40 \mathrm{~mm}$. The direct shear test was conducted to simulate the shear condition of the soil under a short-term condition (during construction and at the end of construction of the BRE wall) and to obtain the total strength parameters. The apparent cohesion and the friction angle were determined under an undrained condition. The cohesive-frictional soils were compacted and sheared at the optimum water content, at which the degree of saturation was between 78 and $87 \%$ (unsaturated soil). Therefore, consolidation and drainage are not an issue for this kind of soil. For an unsaturated soil, the total strength parameters are more appropriate to describe the soil behavior than undrained or drained parameters (Sukmak et al. 2015). The total strength parameters of backfill compacted at a saturation degree of about $70 \%$ under an unconsolidated undrained condition have been used for analysis and simulation of the stability of reinforced embankments (Chai et al. 1994; Bergado et al. 1995).

According to the total stress analysis suggested in the Plaxis manual, the properties of all soil parameters used in 


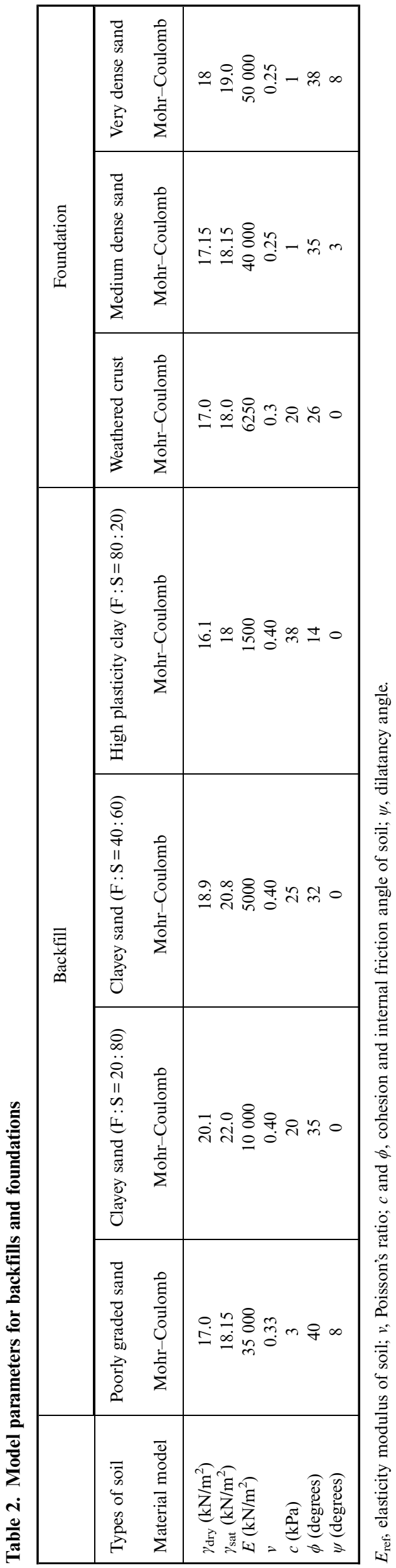

this study were considered as a drained condition. Barkan (1962) proposed that the ranges of Poisson's ratio for sand and unsaturated clay were $0.30-0.35$ and $0.35-0.40$, respectively. Therefore, Poisson's ratio of poorly graded sand was taken as 0.33 and Poisson's ratio of unsaturated clayey sands and clay of high plasticity was taken as 0.40 . The tested soils were compacted at optimum water contents, which were in an unsaturated state. The material properties of the backfill used for the FE simulation are shown in Table 2.

\subsubsection{Foundation}

A linearly elastic, perfectly plastic Mohr-Coulomb model was used to simulate the behavior of all foundation soils. The material properties used for the FE simulations are shown in Table 2.

Suksiripattanapong et al. (2012) used the 2D PLAXIS program to simulate the BRE wall model with a poorly graded sand backfill. The simulated lateral wall movement from this model did not agree with that from the fullscale test. The measured lateral movement was smaller than the simulated lateral movement. The authors speculated that the elastic modulus $\left(E=1875 \mathrm{kN} / \mathrm{m}^{2}\right)$ of the weathered crust foundation layer used in this model was unreasonably low and the inclinometer casing minimized the soil lateral movement. This low modulus was obtained from a one-dimensional consolidation test on an undisturbed sample due to the saturation of the soil sample, which softened the soil. Thus, an attempt was to eliminate the inclinometer casing and the foundation parameter effect by refining all mesh elements and increasing the elastic modulus of the weathered crust foundation layer in the reference numerical model. The elastic modulus $\left(E=6250 \mathrm{kN} / \mathrm{m}^{2}\right)$ was selected by trial and error to match the predicted lateral wall movement, lateral earth pressure, settlement, and bearing stress on the foundation with those measured during and at the end of construction with poorly graded sand backfill. The ratio of the selected $E\left(6250 \mathrm{kN} / \mathrm{m}^{2}\right)$ to the laboratory $E\left(1875 \mathrm{kN} / \mathrm{m}^{2}\right)$ was about 3.3. The selected elastic modulus of the weathered crust layer falls within the range for a medium dense silty sand $\left(E=6000-10000 \mathrm{kN} / \mathrm{m}^{2}\right)$ reported by Bowles (1996) and Kezdi (1974).

\subsection{Wall facing and reinforcement}

\subsubsection{Wall facing}

The wall face was made of segmental concrete panels, which were $1.50 \times 1.50 \times 0.14 \mathrm{~m}$ thick in dimension. The facing panel was modeled as beam (plate) elements. The input parameters for strength and modulus of elasticity are shown in Table 3. Linearly elastic material was used to simulate behavior of wall facing. AASHTO (2002) recommended that the soil-facing panel interface coefficient, $R$ should be $0.75-1.0$, which has been used in the numerical studies by Damians et al. (2015) and Suksiripattanapong et al. (2012). As the variation of this interface coefficient is not large, the effect of interface coefficient was not investigated in this research and it was assumed to be 0.90 for all simulations. 
Table 3. Model parameters for reinforcement and concrete facing

\begin{tabular}{|c|c|c|c|c|}
\hline & Bearing reinforcement (geotextile) & & & Concrete facing (Plate element) \\
\hline $\begin{array}{l}\text { Material model } \\
E A\left(\mathrm{kN} / \mathrm{m}^{2}\right) \\
E I\left(\mathrm{kN} / \mathrm{m}^{2}\right) \\
w(\mathrm{kN} / \mathrm{m} \text { per } \mathrm{m}) \\
v \\
\text { Longitudinal member (SD40) } \\
\text { Transverse member }(\mathrm{Fe} 24) \\
R_{\text {inter }}\end{array}$ & $\begin{array}{l}\text { Elastic } \\
4.5 E+4 \\
- \\
- \\
- \\
\text { Tensile strength (MPa) } \\
\text { Elongation }(\%) \\
\text { Tensile strength (MPa) } \\
\text { Elongation (\%) } \\
\text { Poorly graded sand } \\
\text { Clayey sand (F:S = } 20: 80) \\
\text { Clayey sand (F:S = } 40: 60) \\
\text { High plasticity clay }(\mathrm{F}: \mathrm{S}=80: 20)\end{array}$ & $\begin{array}{l}n=2 \\
n=3 \\
n=2 \\
n=3 \\
n=2 \\
n=3 \\
n=2 \\
n=3\end{array}$ & $\begin{array}{l}560 \\
15 \\
402 \\
21 \\
0.65 \\
0.75 \\
0.60 \\
0.70 \\
0.55 \\
0.65 \\
0.38 \\
0.40\end{array}$ & $\begin{array}{l}\text { Elastic } \\
3.556 E+6 \\
5808 \\
3.36 \\
0.15 \\
-\end{array}$ \\
\hline
\end{tabular}

$R_{\text {inter, }}$ Soil-reinforcement interaction ratio.

\subsubsection{Reinforcement}

The bearing reinforcement [three-dimensional (3D) material] was modeled as two-dimensional (2D) continuous sheet elements (called geotextile elements) in the manual with a linear elastic material. The required equivalent parameters for $2 \mathrm{D}$ geotextile elements were soil-reinforcement interaction ratio, $R_{\text {inter }}$ and axial stiffness per meter, $E A$, which is the product of the elastic modulus $(E)$ of reinforcement $(=20 \mathrm{GPa})$ and its cross-sectional area per unit width $(A)$. The linearly elastic-perfectly plastic model was used to simulate the interaction between soil and bearing reinforcement. The input parameters of reinforcement are shown in Table 3, where $E A=4.5 \times 10^{4} \mathrm{kN} / \mathrm{m}$.

\subsubsection{Soil-reinforcement interaction}

The soil-reinforcement interaction ratio, $R_{\text {inter }}$ is defined as the ratio of the shear strength of soil-reinforcement interface to the shear strength of the surrounding soil (Vermeer and Brinkgreve 1995). $R_{\text {inter }}$ in the numerical model was determined by simulating large-scale laboratory pullout test results. The geotextile elements, which cannot resist the bending moment, were employed to model the bearing reinforcement with longitudinal and transverse (bearing) members. The contribution of both friction and bearing resistances was converted to the equivalent frictional resistance. This method was used by Bergado et al. (2003), Khedkar and Mandal (2009), Abdelouhab et al. (2011) and Suksiripattanapong et al. (2012). The equivalent frictional resistance is represented by the soil-structure interaction ratio, $R_{\text {inter }}$. The linearly elastic-perfectly plastic model was used to simulate the interaction between soil and bearing reinforcement.

\subsection{Staged construction}

In order to model the actual construction stages, the reinforced backfill and the retained backfill were modeled in eight layers. Each layer was constructed in the following stages.

- Stage 1: the first concrete panel (plate element) was set up, the first soil layer was placed and compacted into a layer thickness of $0.375 \mathrm{~m}$, and then the first bearing reinforcement (geotextile element) was placed on the first compacted soil layer.

- Stage 2: the second soil layer was placed and compacted into a lift thickness of $0.75 \mathrm{~m}$ and then the second bearing reinforcement was placed on the second soil layer.

- Stage 3: the second concrete panel was set up, the third soil layer was placed and compacted into a layer thickness of $0.75 \mathrm{~m}$, and then the third bearing reinforcement (geotextile element) was placed on the third compacted soil layer.

- These stages were repeated up to the wall height of $6 \mathrm{~m}$.

The backfill compaction during construction of the BRE wall model was simulated by applying a uniform vertical stress equal to $8 \mathrm{kPa}$ to the entire surface of each newly placed soil layer in both reinforced and unreinforced zones. This vertical stress was removed before the placement of the next soil layer. This intensity of the vertical stress was used to simulate compaction effects (Hatami and Bathurst 2005, 2006).

\section{FINITE-ELEMENT ANALYSIS}

\subsection{Soil-structure interaction ratio, $\boldsymbol{R}_{\text {inter }}$}

Several laboratory pullout tests were carried out in a metallic box of $2.6 \mathrm{~m} \times 0.6 \mathrm{~m} \times 0.6 \mathrm{~m}$ high. The longitudinal member of the reinforcement was $12 \mathrm{~mm}$ in diameter and $2.6 \mathrm{~m}$ long. The width of the transverse member was $150 \mathrm{~mm}$. The number of transverse members, $n$ used in this study were $n=2$ and 3 . The $R_{\text {inter value was }}$ dependent on the number of transverse members and soil 


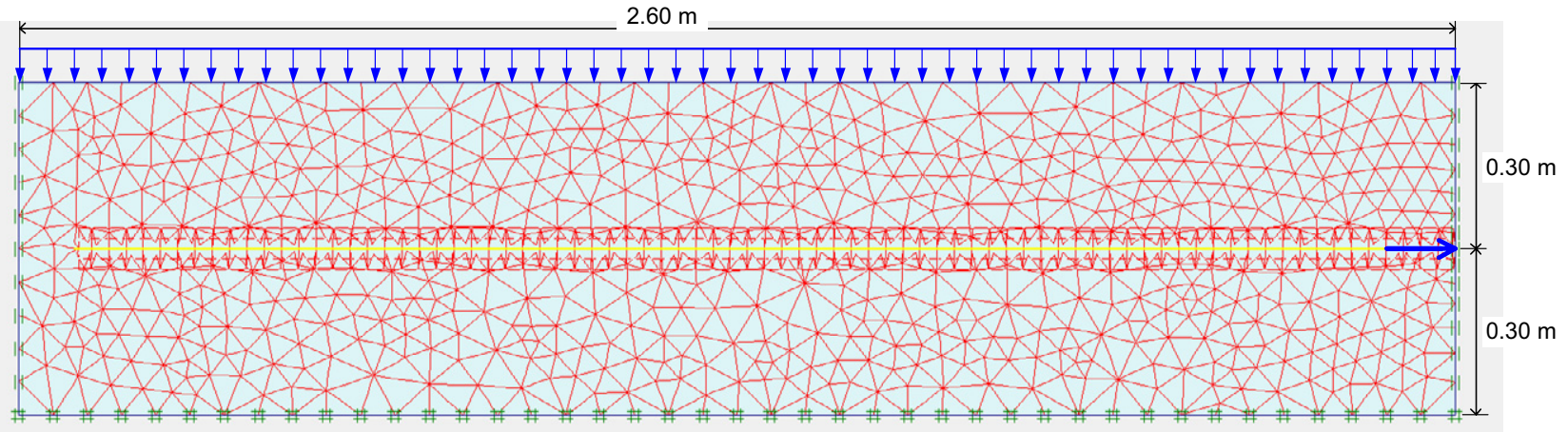

Figure 6. Finite-element model for pullout tests

properties. The laboratory pullout test was modeled as a plane strain problem as shown in Figure 6. The nodal points at the bottom boundary were fixed in both directions and those on the side boundaries were only fixed in the horizontal direction.

The soil-bearing reinforcement interaction ratio for a specific number of transverse members was back-calculated from the laboratory pullout tests by Horpibulsuk and Niramitkornburee (2010) for poorly graded sand ( $\mathrm{F}: \mathrm{S}=2: 98)$ and by Sukmak et al. (2015) for clayey sands $(F: S=20: 80)$, clayey sand $(F: S=40: 60)$, and high-plasticity clay $(F: S=80: 20)$. Several pullout tests at different applied normal stresses were modeled $\left(\sigma_{\mathrm{n}}=30,50\right.$, and $\left.90 \mathrm{kPa}\right)$ in order to simulate the reinforcement at different depths in the wall. In the backcalculation, the input parameter for the geotextile element is the equivalent axial stiffness. The input parameters for soils and reinforcement were provided in Tables 2 and 3.

Figures $7 \mathrm{a}$ and $7 \mathrm{~b}$ show the measured and simulated total pullout force and displacement relationships of the bearing reinforcement with 2 and 3 transverse members ( $n=2$ and 3), respectively embedded in clayey sand $(\mathrm{F}: \mathrm{S}=20: 80)$ as an example. This method can be used to determine $R_{\text {inter }}$ for other $n$ values. The $R_{\text {inter value was }}$ varied until the modeled curves coincided with the laboratory curves. The numerical curves well reproduced the curves of laboratory tests as a function of the applied pullout force. The numerical simulation captured the behavior of bearing reinforcement, in which the total pullout resistance increased with an increase in the applied normal stress for all tested soils. The numerical model slightly overestimated the pullout resistance in the initial portion when the number of transverse members, $n=3$. This slight difference is not expected to affect the accuracy of the numerical model to simulate the behavior of the BRE wall.

The relationships between the soil-structure interaction and the fine content for $n=2$ and 3 are shown in Figure 8. The $R_{\text {inter }}$ values decreased with an increase in fine content, which also reduced the interface stiffness as well as the shear strength. The soil-structure interactions varied as an increase of fine content in the ranges of $0.65-0.38$ and $0.75-0.40$ for $n=2$ and 3, respectively. The relationships between $R_{\text {inter }}$ and the fine content for $n=2$ and 3 are represented by polynomial functions in the

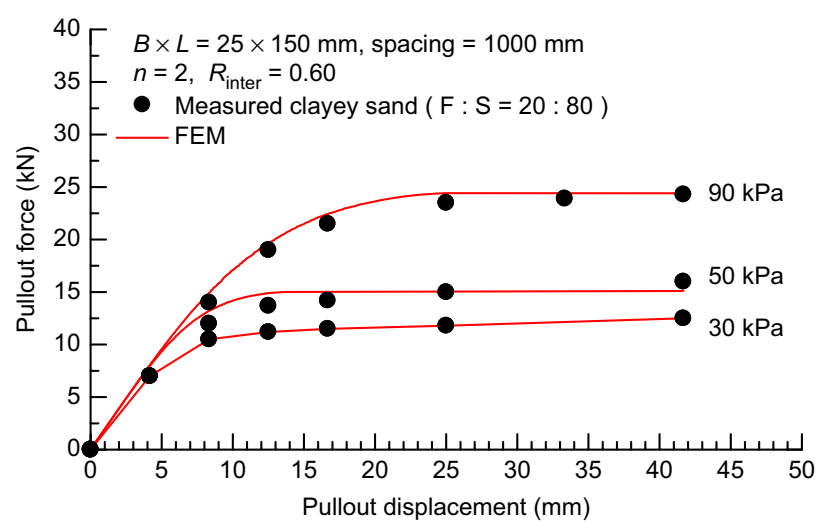

(a)

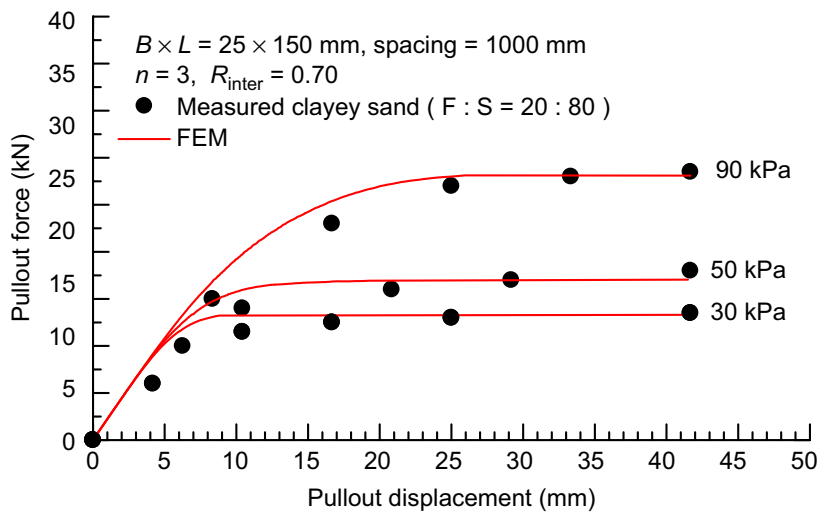

(b)

Figure 7. Simulated and measured pullout test results of the bearing reinforcement: (a) number of transverse members, $n=2$; (b) number of transverse members, $n=3$

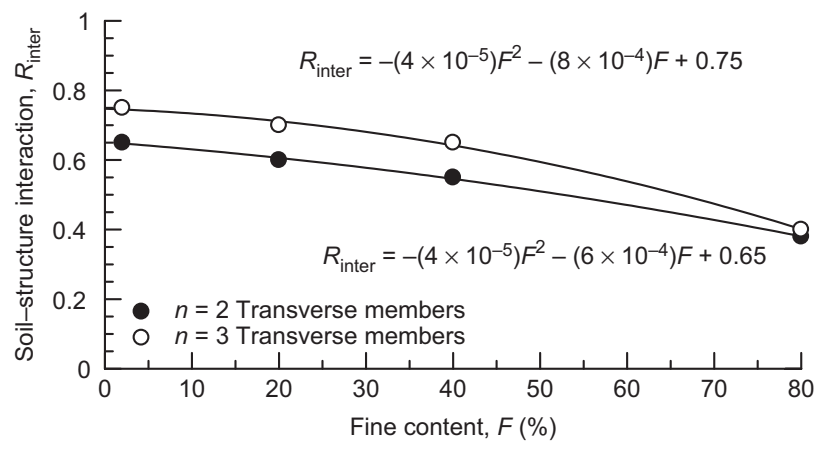

Figure 8. Relationship between soil-structure interaction and fine content 
following forms

$$
\begin{aligned}
& R_{\text {inter }}=-\left(4 \times 10^{-5}\right) F^{2}-\left(6 \times 10^{-4}\right) F+0.65 \\
& \text { for } 2<F<80 \% ; n=2 \\
& R_{\text {inter }}=-\left(4 \times 10^{-5}\right) F^{2}-\left(8 \times 10^{-4}\right) F+0.75 \\
& \text { for } 2<F<80 \% ; n=3
\end{aligned}
$$

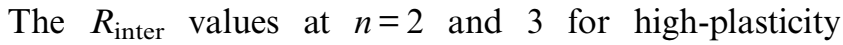
clayey soil ( $\mathrm{F}: \mathrm{S}=80: 20)$ were nearly same because the development in the bearing pullout resistance was comparatively low for $F>80 \%$ (Sukmak et al. 2015). The

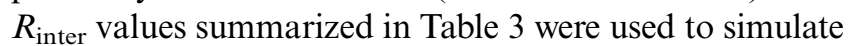
the field performance of the BRE wall.

\subsection{Behavior of BRE wall with different types of soil}

\subsubsection{Bearing stress}

The relationships between bearing stress and construction in both the reinforced zone $(0.5$ and $2.4 \mathrm{~m}$ from the wall facing) and the unreinforced zone $(4.5 \mathrm{~m}$ from the wall facing) for poorly graded sand $(F: S=2: 98)$, clayey sand $(\mathrm{F}: \mathrm{S}=20: 80)$ and $(\mathrm{F}: \mathrm{S}=40: 60)$, and high-plasticity clay $(F: S=80: 20)$ are shown in Figure 9. The calculated overburden stress $\left(\sigma_{\mathrm{v}}=\gamma z\right)$ at different construction stage is also shown in Figure 9. The bearing stresses at the bottom of the earth wall with backfill soils increased during construction due to the backfill placement. After the completion of construction, the bearing stress changed insignificantly with time. For the poorly graded sand backfill, the simulated bearing stresses for both reinforced and unreinforced zones are in good agreement with the measured ones. At $2.4 \mathrm{~m}$ away from the wall face, the measured bearing stress was lower than the simulated one due to the non-uniformity of compaction at this particular location; therefore, the earth pressure cell sank into the ground at the vertical pressure of $32 \mathrm{kPa}$ (the second loading) (Suksiripattanapong et al. 2012). At 0.5 and $4.5 \mathrm{~m}$ away from the wall face, the simulated bearing stress and $\sigma_{\mathrm{v}}$ were essentially the same prior to the end of construction. The simulated bearing stresses at 0.5 and $4.5 \mathrm{~m}$ at the end of construction were higher and lower than $\sigma_{\mathrm{v}}$, respectively because of the overturning effect. The bearing stress of the clayey sand $(F: S=20: 80)$ is the highest due to its highest maximum dry density. In other words, the bearing stress decreased as the maximum dry density decreased. It clearly shows that the bearing stress depended on the density of backfill.

Figure 10 shows the distributions of the measured and simulated bearing stresses and the calculated overburden stress $\left(\sigma_{\mathrm{v}}=\gamma z\right)$ at the end of construction. The measured and simulated bearing stresses show a consistent reduction from the wall facing. A similar behavior of the bearing stresses decreasing with the distance from the wall facing was observed in the instrumented concrete facing reinforcement walls built on rigid foundations (Huang et al. 2009; Damians et al. 2015). The simulated bearing stress in the reinforced zone decreased from the front to the back because the BRE wall behaved as a rigid body built on the relatively firm foundation retaining the unreinforced backfill. The maximum bearing stress at the toe of the
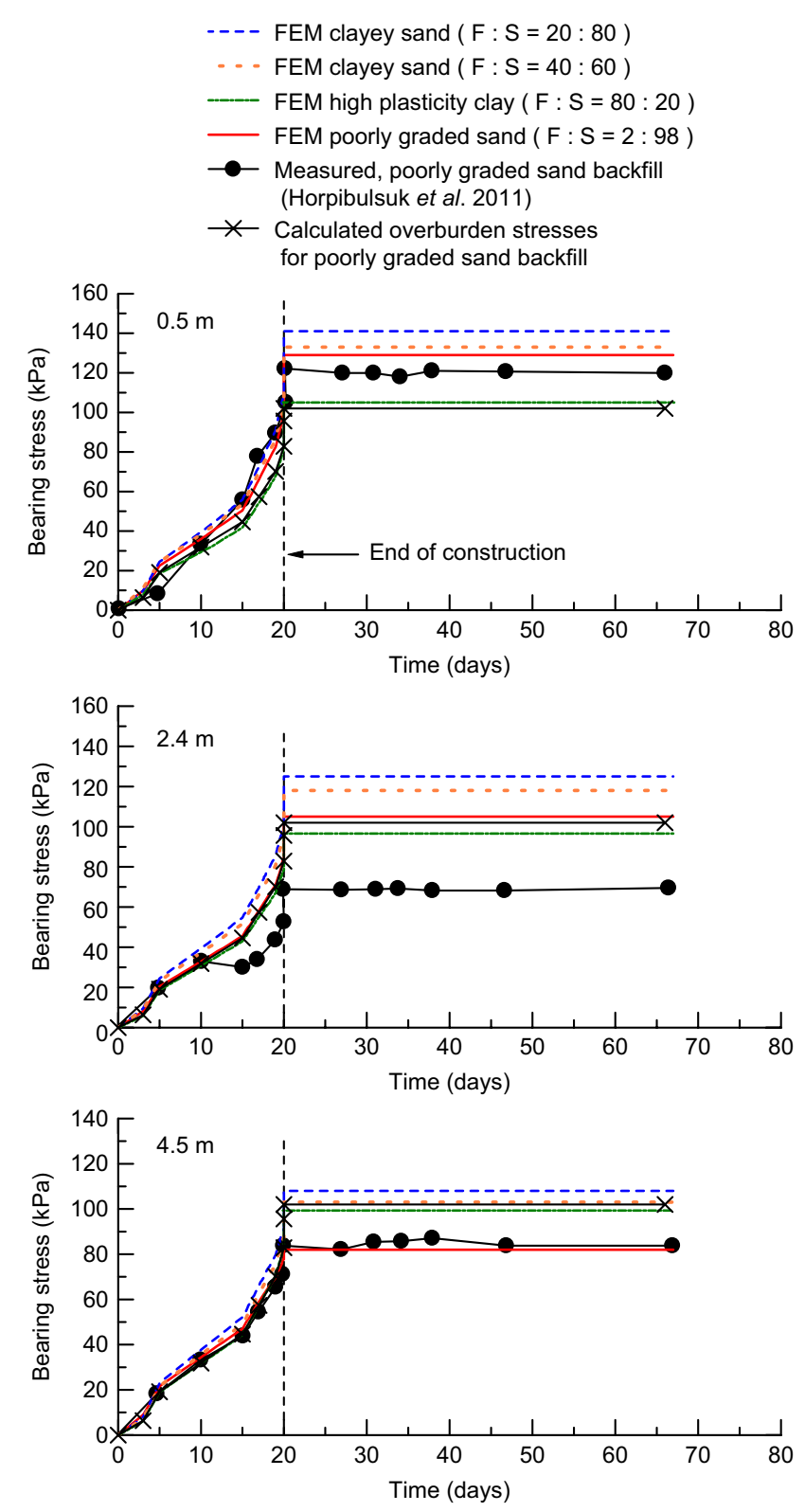

Figure 9. Comparison between the simulated and measured settlements with construction time for different backfill

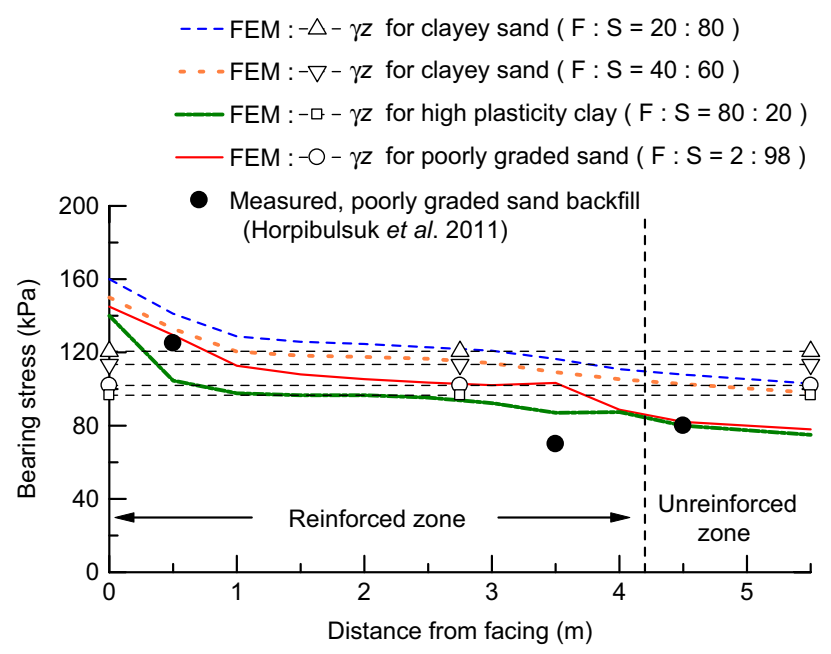

Figure 10. Measured and simulated bearing stresses and calculated overburden stresses for different backfill 
wall facing resulted from the eccentric load caused by the lateral thrust from the unreinforced backfill and the vertical load from the weight of segmental concrete panels. These simulated results are in agreement with the measured toe loads recorded from the instrumented field wall. Damians et al. (2013) concluded that the vertical toe loads were higher than the self-weight of the facing units. At $2.75 \mathrm{~m}$ away from the wall facing, the simulated bearing stresses under all the backfills were close to the calculated overburden stress. The bearing stress in the unreinforced zone insignificantly decreased.

\subsubsection{Settlement}

The measured and simulated settlements of the BRE wall with different backfills are shown in Figure 11. The measured settlements from three settlement plates (at 0.8 , 2.0 , and $4.0 \mathrm{~m}$ from the wall facing) under the BRE wall with poorly graded sand backfill were compared with the simulation. The base settled fast during the construction. As the settlement is dependent upon staged construction, the sudden settlement occurred due to the sudden loading at day 20 (8th to 10th loading) as shown in Figure 3a. The simulated settlements at the end of construction with the poorly graded sand backfill were much closer to the measured ones. After the completion of the construction (at

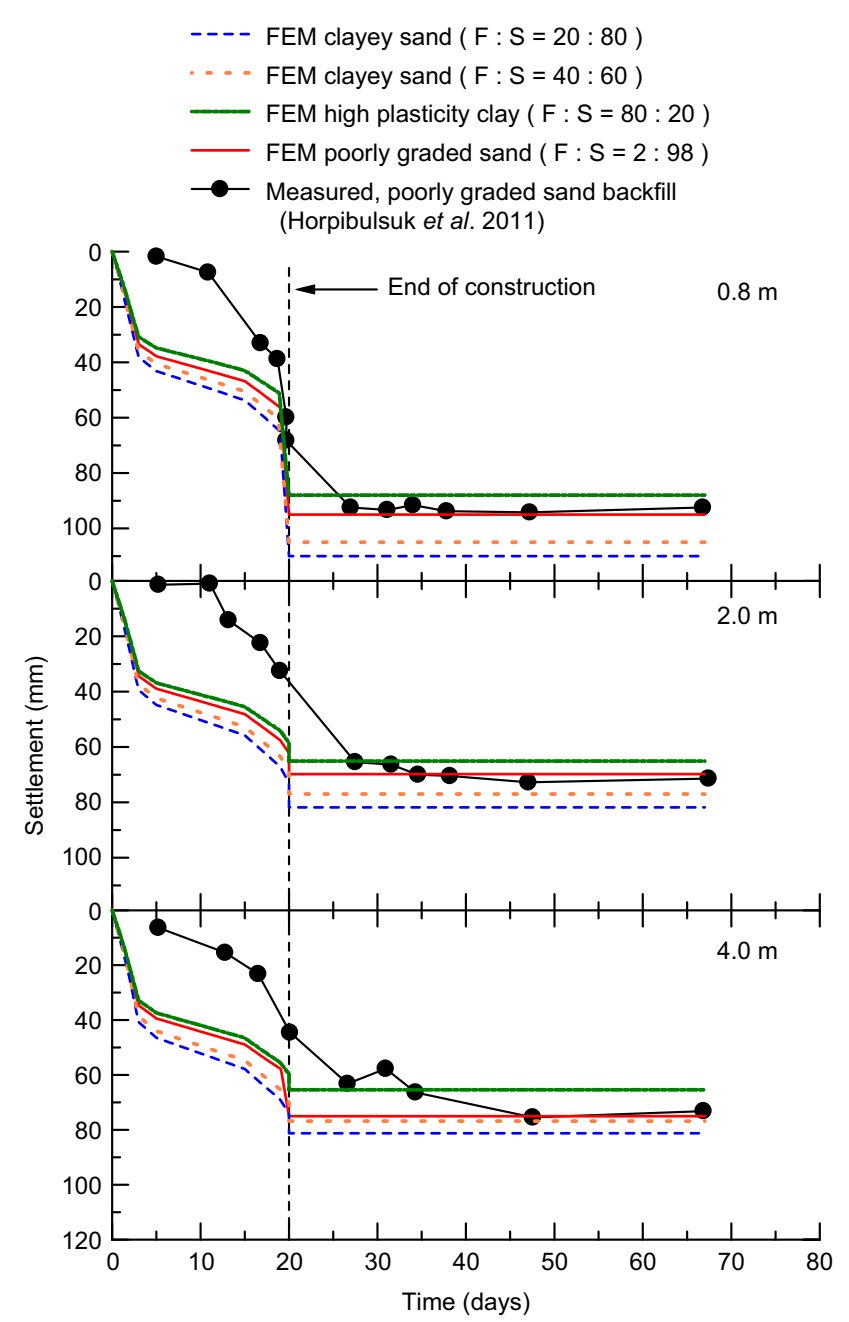

Figure 11. Measured and simulated settlements with construction time for different backfill
20 days), the settlement increased insignificantly. The difference in the measured and simulated settlement before the end of construction ( $<20$ days) is caused by different drainage conditions. In the simulation, the fully-drained condition was assumed for the compacted unsaturated soil (no excess pore pressure) while the in-situ drained condition might slightly divert from the assumption.

The settlements of the walls with the backfills having $\mathrm{F}: \mathrm{S}=20: 80$ and $\mathrm{F}: \mathrm{S}=80: 20$ were the largest and smallest due to the highest and lowest bearing stresses on the base of the wall (Figure 10), respectively. The settlement decreased from the facing of the wall to the unreinforced zone. The settlement was highest at the toe of the wall because a portion of the self-weight of the backfill was transferred from the reinforcement to the facing of the wall and the wall also slightly rotated thus increasing the pressure at the toe (Rowe and Skinner 2001).

\subsubsection{Horizontal wall movement}

The simulated and measured horizontal wall movements with different backfills are compared and shown in Figure 12. The simulated result of the wall with the fill of $\mathrm{F}: \mathrm{S}=80: 20$ is not included because of its excessive horizontal wall movement. The comparison between the measured and simulated horizontal wall movements with the backfill of $\mathrm{F}: \mathrm{S}=2: 98$ is considered to be reasonable. The horizontal wall movements were the sum of the horizontal movement during construction (caused by the lateral movement of reinforced and unreinforced soil zones) and the foundation wall movement and settlement. The horizontal wall movements increased as the fine content increased due to the decrease in shear strengths of the backfills. The increase of the fine content changed the

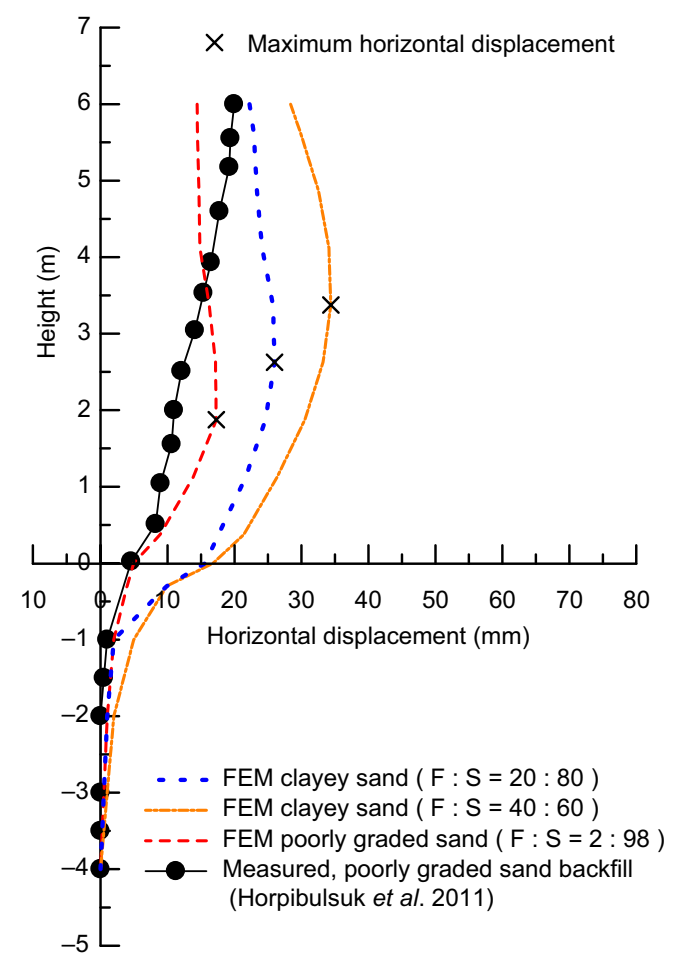

Figure 12. Comparison between the measured and simulated horizontal wall movement for different soil embankments 
location of the maximum wall movement higher up from $2.0 \mathrm{~m}$ for $\mathrm{F}: \mathrm{S}=2: 98$ to $6.0 \mathrm{~m}$ (the top of the wall) for $\mathrm{F}: \mathrm{S}=80: 20$.

Figure 13 shows the simulated horizontal movement of the unreinforced soil zone at $4.5 \mathrm{~m}$ away from the facing of the wall. The simulated horizontal movement of the unreinforced soil zone increased with the increase of fine content as the performance of the reinforced zone decreased. The performance of the reinforced zone was represented by the horizontal movement ratio

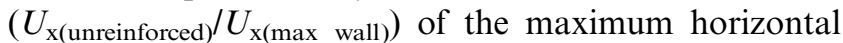
movement of the unreinforced zone to the maximum horizontal movement of the wall facing. This ratio indicated the ability of the reinforced zone to resist the horizontal movement (pressure) of the unreinforced zone. When this ratio is low, the BRE wall has better performance due to its increased stability. At the locations of the maximum wall movement with each backfill, the horizontal movement ratios are $0.36,0.46,0.56$, and 0.84 for $F: S=2: 98,20: 80 ; 40: 60$, and $80: 20$, respectively. The high horizontal movement ratio for $\mathrm{F}: \mathrm{S}=80: 20$ shows that the BRE wall could not resist the horizontal movement (pressure) of the unreinforced zone. In addition, the maximum horizontal movement occurred at the top of the wall (6 m high). This characteristic implies that the BRE wall tends to rotate around the toe.

Figure 14 shows the relationship between the maximum horizontal wall movement and the fine content. This

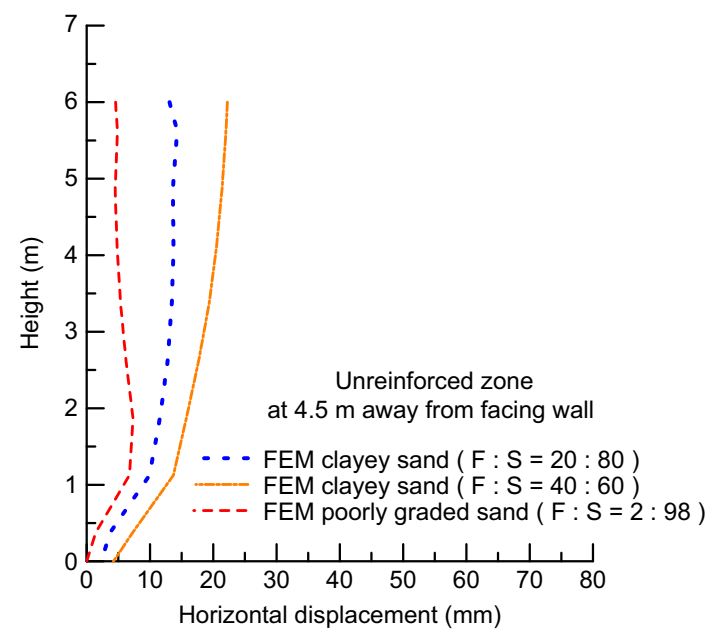

Figure 13. Simulation horizontal movement of unreinforced zone at $4.5 \mathrm{~m}$ away from facing wall for different soil embankments

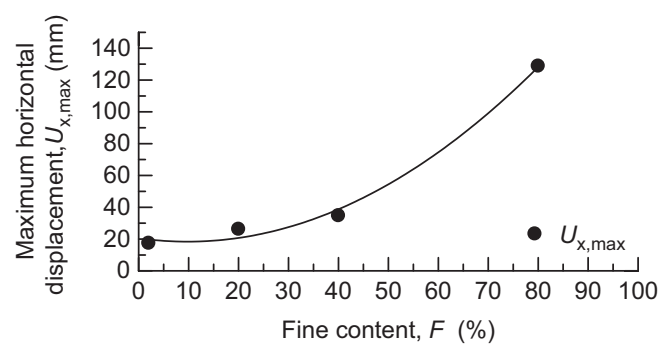

Figure 14. Relationship between maximum horizontal wall movement and fine content relationship can be expressed by a polynomial function. The maximum horizontal wall movement significantly increased with the fine content especially for $F>45 \%$. Thus, based on this specific BRE wall feature and the constitutive models, the selected soil that can minimize horizontal movement should not contain fine contents higher than $45 \%$. The large horizontal displacement for $\mathrm{F}: \mathrm{S}=80: 20$ may result from the low shear strength of the backfill and the low bearing resistance due to the failure mode approaching to the punching shear (Sukmak et al. 2015).

\subsubsection{Lateral earth pressure}

Figure 15 shows the measured and simulated lateral earth pressures, $\sigma_{\mathrm{h}}$ for different backfills. $\sigma_{\mathrm{h}}$ is the ratio of maximum tensile force to vertical spacing. It is noted from this analysis that the maximum tensile force for each of the reinforcements occurred at the connection between wall face and reinforcement to resist the horizontal movement of the wall facing, irrespective of the fine content. This result is in agreement with the previous studies by Suksiripattanapong et al. (2016) for sand backfill. For the coarse-grained soil with $\mathrm{F}: \mathrm{S}=2: 98$, the coefficient of at-rest earth pressure, $K_{\mathrm{o}}$, can be estimated by using the empirical relationship (Jaky 1944) as shown in Equation 3. For the fine-grained soils with $\mathrm{F}: \mathrm{S}=20: 80$, $40: 60$, and $80: 20$, the values of $K_{\mathrm{o}}$ were obtained from the $K_{\mathrm{o}}$ consolidated simulation in the PLAXIS program. The coefficient of Rankine's active earth pressure is given in Equation 4, which was used for all soil backfills.

$$
\begin{aligned}
& K_{\mathrm{o}}=1-\sin \phi \text { for } \mathrm{F}: \mathrm{S}=2: 98 \\
& K_{\mathrm{a}}=\tan ^{2}\left(45-\frac{\phi}{2}\right) \\
& \text { for } \mathrm{F}: \mathrm{S}=2: 98,20: 80,40: 60, \text { and } 80: 20
\end{aligned}
$$

From the simulated results, the maximum tension plane occurred at the connections between the reinforcement and the wall facing due to the bearing reinforcement embedded in backfill were stretched to resist the horizontal movement of the wall facing. Figure 15 clearly shows that the lateral earth pressure in each reinforcement approached the at-rest earth pressure as the fine content increased. For $\mathrm{F}: \mathrm{S}=2: 98$, the comparison between the measured and simulated lateral earth pressures is considered to be reasonable. The calculated $\sigma_{\mathrm{h}}$ was close to the at rest-earth pressure when the wall height was greater than $3 \mathrm{~m}$. Below this height, the calculated $\sigma_{\mathrm{h}}$ approached to the Rankine active earth pressure $\left(\sigma_{\mathrm{h}}=\sigma_{\mathrm{v}} K_{\mathrm{a}}\right)$, which is in agreement with the recommendation by AASHTO (2002). However, for $\mathrm{F}: \mathrm{S}=20: 80$ and $40: 60$, the simulated lateral earth pressures are between the calculated active earth pressure $\left(\sigma_{\mathrm{h}}=\sigma_{\mathrm{v}} K_{\mathrm{a}}-2 c \sqrt{K_{\mathrm{a}}}\right)$ and at-rest earth pressure $\left(\sigma_{\mathrm{h}}=K_{\mathrm{o}} \sigma_{\mathrm{v}}\right)$. Moreover, for $\mathrm{F}: \mathrm{S}=80: 20$, the simulated lateral earth pressure was essentially the same as the calculated at-rest earth pressure. This result is similar to that obtained by Chai (1992), in which he studied the interaction behavior between steel grid reinforcements and lateritic backfill soil. 


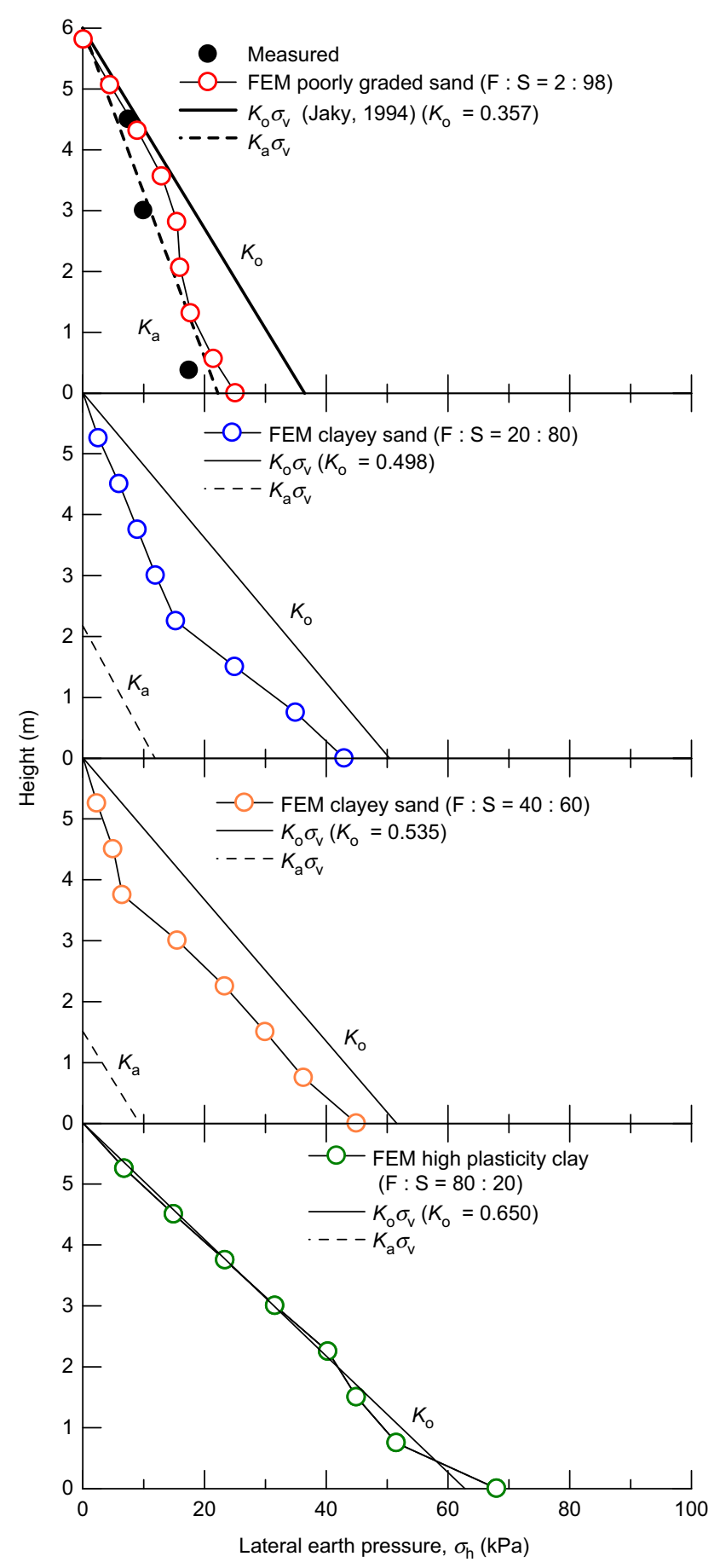

Figure 15. Measured and simulated lateral earth pressure distributions for different backfill

Figure 16 shows the simulated maximum tension force $T_{\max }$ profile at the connection between the wall facing and the reinforcement. The $T_{\max }$ increased with the depth of the wall due to the higher overburden pressure for a particular backfill. A higher $\mathrm{F}$ resulted in a higher $T_{\max }$ for each reinforcement level. The results on the change of the tension forces along the reinforcement are similar to the previous research for metallic weld wire meshes (Damians et al. 2013) and bearing reinforcement (Suksiripattanapong et al. 2016) that the tension force gradually decreased with the distance away from wall facing.

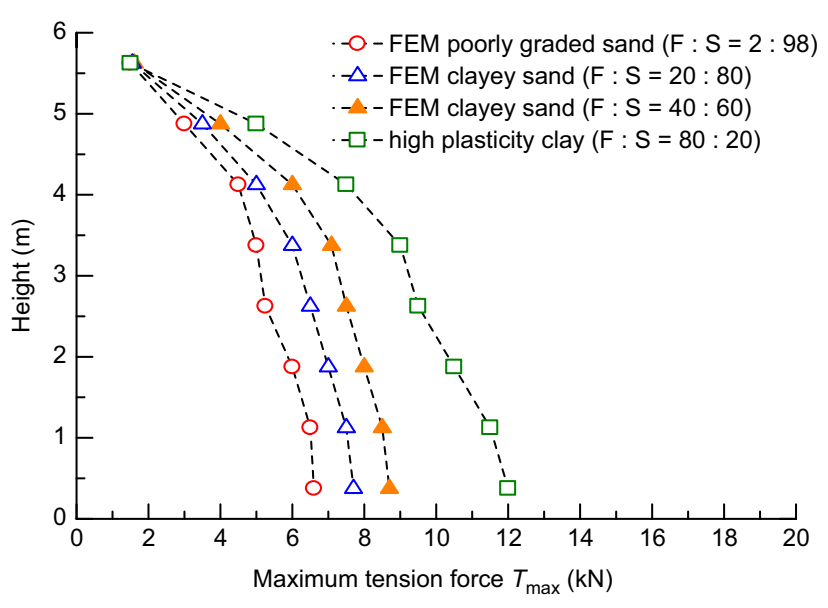

Figure 16. Simulated maximum tension force at the connection between reinforcement and wall facing

The overall results from the numerical analysis, including bearing stress, settlement, horizontal wall movement, and lateral earth pressure in this study provides an understanding of the influence of fine content on the behavior of the BRE wall. However, to confirm the results from the numerical analysis, full-scale tests of BRE walls with cohesive-frictional backfill are needed.

\subsection{Parametric study on horizontal wall displacement}

The influence of soil-structure interaction, foundation, and stiffness of reinforcement on the horizontal wall displacement was studied for different types of backfill. Horizontal wall deformations are especially important for serviceability of MSE structures. This parametric study was conducted based on the reference numerical BRE wall model discussed above and their parameters are defined and given in Figure 2, Tables 1-3, including geometry, foundation, backfill, and structural elements. These parameters were adopted for all analyses unless otherwise indicated. This study was conducted by varying one parameter of soil-structure interaction, foundation, or stiffness of reinforcement at a time while all other parameters were kept constant.

\subsubsection{Influence of soil-structure interaction ratio, $\mathbf{R}_{\text {inter }}$} Figure 17 shows the relationship between the maximum horizontal displacement and the soil-structure interaction ratio, $R_{\text {inter }}$. The $R_{\text {inter }}$ values varied between 0.2 to 1.0 to represent the effect of the number of transverse members and the transverse member interference, which is affected by the transverse member spacing. $R_{\text {inter }}$ for bearing reinforcement was approximately $0.6-0.9$ for $n=2-3$ without any transverse member interference (Suksiripattanapong et al. 2016) when $S / B$ is greater than the individual failure spacing ratio $\left(S_{2} / B\right)$. The $R_{\text {inter }}$ might decrease to 0.3 for very high transverse member interference, which is equal to that of strip reinforcement (Yu and Bathurst 2015). The $S_{2} / B$ values for different $F$ can be found in Sukmak et al. (2015) and Sukmak et al. (2016). The maximum horizontal displacement rapidly decreased with an increase of the soil-structure interaction 


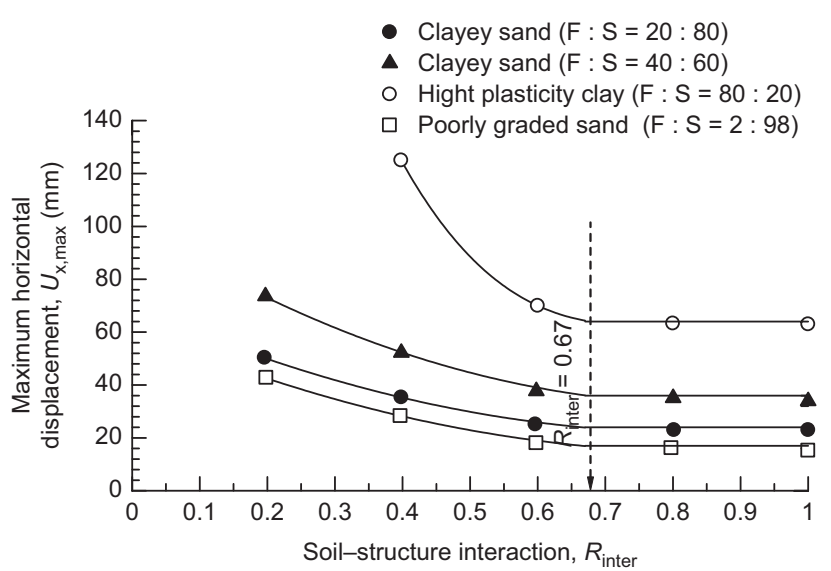

Figure 17. Relationship between maximum horizontal displacement and soil-structure interaction ratio for different backfill

ratio and then became insensitive to the soil-structure interaction ratio after the ratio was approximately 0.67 for all backfill materials. When the soil-structure interaction ratio was less than 0.67 , the large displacement is due to slip failure between reinforcement and soil. Rowe and Ho (1998) indicated that the variation in the horizontal displacement was insignificant when the interface coefficient decreased from 1.0 to 0.67 . The present results furthermore illustrated that the transitional $R_{\text {inter }}$ that separates low and high horizontal movement was essentially the same and equal to 0.67 , irrespective of the fine content.

According to Figure 8, for $\mathrm{F}: \mathrm{S}=2: 98,20: 80$, and $40: 60$, the $R_{\text {inter }}$ of $n=3$ (without any transverse member interference) was equal to $0.75,0.70$, and 0.65 , respectively, which were close to or higher than 0.67 . This implies that the bearing reinforcements with at least three transverse members at $S / B>S_{2} / B$ when used in a BRE wall will provide small horizontal wall movement for $F<40 \%$. It is evident that the change in $U_{\mathrm{x}, \max }$ when $R_{\text {inter }}<0.67$ is significant for $\mathrm{F}: \mathrm{S}=80: 20$, compared to other $\mathrm{F}: \mathrm{S}$ ratios.

\subsubsection{Influence of reinforcement stiffness, EA}

The variations of the maximum horizontal displacement with the axial stiffness of reinforcement are shown in Figure 18. These results were obtained by varying the reinforcement stiffness, $E A$ in the range of 500$500000 \mathrm{kN} / \mathrm{m}$ with all other parameters kept the same. It is noted that typically $E A$ varies between $2.0 \times 10^{4}$ and $9.0 \times 10^{4} \mathrm{kN} / \mathrm{m}$. The wider range of $E A$ in this study was selected for better interpretation of the simulated results. The axial stiffness values were presented in a logarithmic scale. Figure 18 shows that the tendency of the horizontal displacement increased with the decrease in the axial stiffness. These results are similar to those from the parametric studies investigated by Rowe and Ho (1997), Bergado et al. (2000) and Youwai and Bergado (2004).

The horizontal wall displacement increased significantly at the axial stiffness lower than $45000 \mathrm{kN} / \mathrm{m}$ (referred to as transitional stiffness) for $\mathrm{F}: \mathrm{S}=2: 98$ and

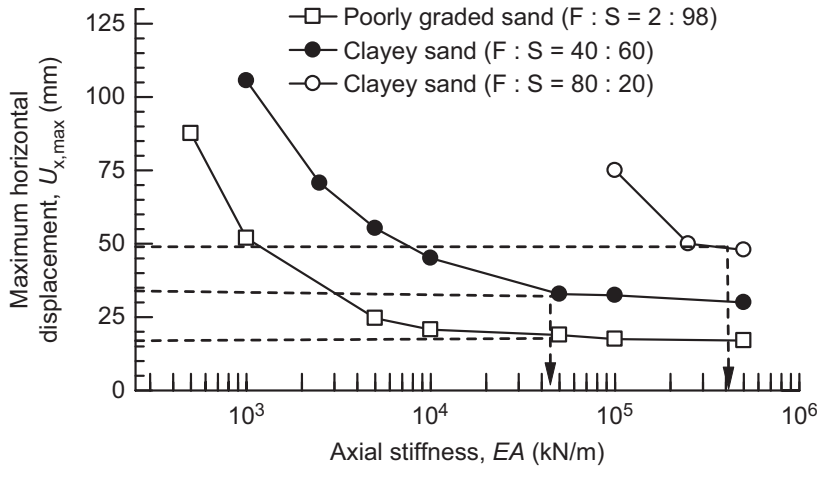

Figure 18. Relationship between maximum horizontal displacement and axial stiffness

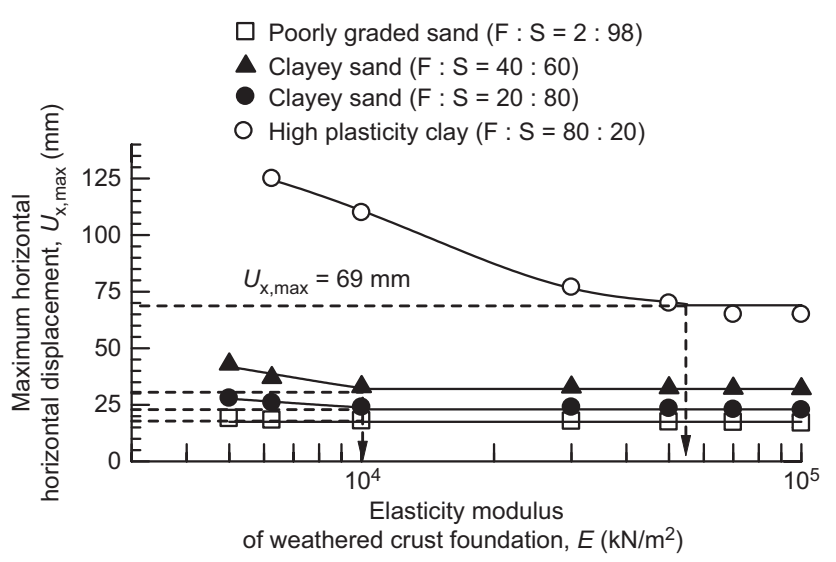

Figure 19. Influence of elastic modulus of foundation

$40: 60$, but the change in the horizontal displacement was not significant at higher stiffness. The transitional stiffness for $\mathrm{F}: \mathrm{S}=80: 20$ was $400000 \mathrm{kN} / \mathrm{m}$, which is almost ten times that for $F: S=2: 98,40: 60$. The low axial stiffness should not be used in practice to avoid large horizontal wall displacement. In other words, more $E A$ is required for a higher fine content for the same reinforcement dimension to attain the same horizontal displacement. Rowe and Ho (1998) stated that the strain (deformation) development within the reinforced zone was restricted considering that the strain compatibility existed between the reinforcement and the soil. Thus, higher axial stiffness resulted in the smaller horizontal displacement (smaller strain).

\subsubsection{Influence of foundation}

The foundation type has an influence on the overall behavior of reinforced soil structures; hence, it is worth considering the horizontal displacement of the wall supported either on a firm foundation or on a soft foundation. The influence of the foundation was investigated by varying elasticity modulus $(E)$ of the weathered crust layer while the thickness of this layer was kept constant as shown in Figure 19. The range of elasticity modulus was $5000-100000 \mathrm{kN} / \mathrm{m}^{2}$, which was simulated for loose soil to dense soil foundation according to Bowles (1996) and Kezdi (1974).

Figure 19 shows that the maximum horizontal wall displacement changed insignificantly when the elasticity 
modulus of the weathered crust foundation was higher than $10000 \mathrm{kN} / \mathrm{m}^{2}$ for $\mathrm{F}: \mathrm{S}=2: 98,20: 80$, and $40: 60$ and $45000 \mathrm{kN} / \mathrm{m}^{2}$ for $\mathrm{F}: \mathrm{S}=80: 20$.

The horizontal displacement of the wall increased as the elasticity modulus of the foundation decreased because of the increase in lateral and vertical (settlement) movements of the foundation. The small horizontal displacement occurred at the toe of the wall facing when it was supported on the firm foundation with an elastic modulus higher than $\left(10000 \mathrm{kN} / \mathrm{m}^{2}\right)$ for $\mathrm{F}: \mathrm{S}=2: 98$ and $20: 80$ and higher than $45000 \mathrm{kN} / \mathrm{m}^{2}$ for $\mathrm{F}: \mathrm{S}=80: 20$ and the maximum horizontal movement was found at about the middle of the wall height. This results show that the $E$ value must be determined with a special care.

For a soft (loose) foundation $\left(E<5000 \mathrm{kN} / \mathrm{m}^{2}\right)$, the maximum lateral movement occurred at the top of the wall for $\mathrm{F}: \mathrm{S}=20: 8040: 60$, and $80: 20$. This characteristic implies that the BRE wall tended to rotate forward around the toe of the wall due to the combined effects of the movement of the foundation and the active lateral earth pressure from the unreinforced backfill. This finding is consistent with the test data of the MSE wall on soft Bangkok clay reported by Bergado et al. (1995). The foundation type significantly affected the pattern of lateral wall movement.

\section{CONCLUSIONS}

This paper presents a numerical parametric study on behavior of BRE walls with different backfill properties using the numerical software PLAXIS 2D. The backfill materials consisted of four types of soils, which were mixtures of silty clay and sand at different fine contents of $2,20,40$, and $80 \%$ by dry weight. Moreover, the influence of several parameters (soil-structure interaction, foundation, and stiffness of reinforcement) on the horizontal wall deformations was studied. The overall results from the numerical analysis in this study can provide an understanding of the influence of fine content on the behavior of BRE walls. The following conclusions can be drawn from this study.

(1) The geotextile elements were used to model the bearing reinforcements by converting the contribution of friction and bearing resistances to the equivalent friction resistance. The equivalent friction resistance was represented by the soil-bearing reinforcement interaction ratio, $R_{\text {inter, }}$ which was back-calculated from the laboratory pullout test. The $R_{\text {inter }}$ values decreased following a polynomial function with an increase in the fine content. The soil-structure interactions varied as an increase of the fine content in the ranges of $0.65-0.38$ and $0.75-0.40$ for $n=2$ and 3 , respectively.

(2) The behavior of bearing stresses, settlements, lateral earth pressures, and horizontal wall movement of the BRE wall with different backfill materials during and at the end of construction was simulated. The simulated bearing stress in the reinforced zone decreased from the front to the back because the BRE wall behaved as a rigid body built on the relatively firm foundation retaining the unreinforced backfill. The bearing stress depended on the density of backfill. The foundation settlement decreased from the facing of the wall to the unreinforced zone for all backfills due to the slight rotation of the wall. The relationship between the maximum horizontal wall movement and the fine content can be expressed by a polynomial function. The maximum horizontal wall movement significantly increased as the fine content was more than $45 \%(F>45 \%)$. The increase of the fine content changed the location of the maximum wall movement higher up from the mid to top of the wall. The simulated lateral earth pressure coefficient of the BRE wall tended to approach to the at-rest earth pressure coefficient $\left(K_{\mathrm{o}}\right)$ when the fine content increased.

(3) Soil-structure interaction, stiffness of reinforcement, and foundation affected the horizontal wall deformation, which is especially important for serviceability of the BRE wall. For all backfill materials, the maximum horizontal displacement rapidly decreased with an increase of the soil-structure interaction ratio and then became insensitive to the soil-structure interaction ratio after the ratio was approximately 0.67 . The horizontal displacement of the BRE wall increased significantly for stiffness lower than $45000 \mathrm{kN} / \mathrm{m}^{2}$ when the backfill contained fine content less than $45 \%$, but the change in the horizontal displacement was not significant at the higher stiffness. The horizontal displacement of the wall changed insignificantly when the foundation modulus was higher than $10000 \mathrm{kN} / \mathrm{m}^{2}$. Moreover, for $\mathrm{F}: \mathrm{S}=80: 20$, the maximum horizontal displacement increased significantly when the elastic modulus of the weathered crust foundation was lower than $45000 \mathrm{kN} / \mathrm{m}^{2}$.

(4) The simulation approach presented in this paper successfully investigated the performance of the BRE wall in Thailand. However, to confirm the results from the numerical analysis, full-scale tests of BRE walls with cohesive-frictional backfill are needed.

\section{ACKNOWLEDGMENTS}

This work was financially supported by the Thailand Research Fund under the TRF Senior Research Scholar program Grant No. RTA5680002 and the Ph.D. Royal Jubilee program Grant No. 0117/2554, Suranaree University of Technology, and the Office of Higher Education Commission under NRU project of Thailand. The first author acknowledges the University of Kansas as a host university for his overseas research. 


\section{NOTATION}

Basic SI units are given in parentheses.

$\begin{aligned} c & \text { cohesion of soil }\left(\mathrm{N} / \mathrm{m}^{2}\right) \\ E & \text { elasticity modulus }\left(\mathrm{N} / \mathrm{m}^{2}\right) \\ E A & \text { axial stiffness }(\mathrm{N} / \mathrm{m}) \\ F & \text { fine content (dimensionless) } \\ K_{\mathrm{a}} & \text { active earth pressure coefficient (dimensionless) } \\ K_{\mathrm{o}} & \text { at rest earth pressure coefficient (dimensionless) } \\ K_{\mathrm{p}} & \text { passive earth pressure coefficient (dimensionless) } \\ n & \text { number of transvers members (dimensionless) } \\ R_{\mathrm{inter}} & \text { soil-structure interaction coefficient } \\ S & \text { (dimensionless) } \\ T_{\mathrm{max}} & \text { spacing between the transverse members (m) } \\ v & \text { Poisson's ratio (dimensionless) } \\ \phi_{\mathrm{n}} & \left.\text { applied normal stress (N/m }{ }^{2}\right) \\ \phi & \text { internal friction angle (degrees) } \\ \psi & \text { dilatancy angle (degrees) }\end{aligned}$

\section{REFERENCES}

AASHTO (American Association of State Highway and Transportation Officials) (2002). Standard Specifications for Highway Bridges, 17 th edn. American Association of State Highway and Transportation Officials, Washington, DC, USA.

Abdelouhab, A., Dias, D. \& Freitag, N. (2011). Numerical analysis of the behaviour of mechanically stabilized earth walls reinforced with different types of strips. Geotextiles and Geomembranes, 29, No. 2, 116-129.

Abdi, M. R. \& Zandieh, A. R. (2014). Experimental and numerical analysis of large scale pull out tests conducted on clays reinforced with geogrids encapsulated with coarse material. Geotextiles and Geomembranes, 42, No. 5, 495-504.

Barkan, D. D. (1962). Dynamics of Bases and Foundations, McGraw Hill Book Co., New York, NY, USA.

Bathurst, R. J. (1993). Investigation of footing resistant on stability of large-scale reinforcement soil wall tests. Proceedings of 46th Canadian Geotechnical Conference, Saskatoon, Saskatchewan Canadian Geotechnical Society, Richmond, British Columbia, Canada, pp. 389-398.

Bergado, D. T. \& Teerawattanasuk, C. (2008). 2D and 3D numerical simulations of reinforced embankments on soft ground. Geotextiles and Geomembranes, 26, No. 1, 39-55.

Bergado, D., Chai, J. \& Miura, N. (1995). FE analysis of grid reinforced embankment system on soft Bangkok clay. Computers and Geotechnics, 17, No. 4, 447-471.

Bergado, D. T., Teerawattanasuk, C., Youwai, S. \& Voottipruex, P. (2000). Finite element modeling of hexagonal wire reinforced embankment on soft clay. Canadian Geotechnical Journal, 37, No. 6, 1209-1226.

Bergado, D. T., Youwai, S., Teerawattanasuk, C. \& Visudmedanukul, P. (2003). The interaction mechanism and behavior of hexagonal wire mesh reinforced embankment with silty sand backfill on soft clay. Computers and Geotechnics, 30, No. 6, 517-534.

Biabani, M. M. \& Indraratna, B. (2015). An evaluation of the interface behaviour of rail subballast stabilised with geogrids and geomembranes. Geotextiles and Geomembranes, 43, No. 3, 240-249.

Bowles, J. E. (1996). Foundation Analysis and Design, 5th edn. McGraw Hill, New York, USA.

Chai, J. (1992). Interaction Behavior between Grid Reinforcements and Cohesive Frictional Soils and Performance of Reinforced Wall Embankment on Soft Ground, Doctoral dissertation GT 91-1, Asian Institute of Technology, Bangkok, Thailand.
Chai, J., Saiichai, S. \& Norihiko, M. (1994). Stability analysis of embankment on soft ground (a case study). Soils and Foundations, 34, No. 2, 107-114.

Collin, J. G. (1986). Earth Wall Design, PhD dissertation, University of California, Berkeley, CA, USA.

Damians, I. P., Bathurst, R. J., Josa, A., Lloret, A. \& Albuquerque, P. J. R. (2013). Vertical-facing loads in steel-reinforced soil walls. ASCE Journal of Geotechnical and Geoenvironmental Engineering, 139, No. 9, 1419-1432.

Damians, I. P., Bathurst, R. J., Josa, A. \& Lloret, A. (2015). Numerical analysis of an instrumented steel-reinforced soil wall. $A S C E$ International Journal of Geomechanics, 15, No. 1, 04014037.

Dash, S. K. \& Bora, M. C. (2013). Improved performance of soft clay foundations using stone columns and geocell-sand mattress. Geotextiles and Geomembranes, 41, 26-35.

Esfandiari, J. \& Selamat, M. R. (2012). Laboratory investigation on the effect of transverse member on pull out capacity of metal strip reinforcement in sand. Geotextiles and Geomembranes, 35, 41-49.

Esmaili, D., Hatami, K. \& Miller, G. A. (2014). Influence of matric suction on geotextile reinforcement-marginal soil interface strength. Geotextiles and Geomembranes, 42, No. 2, 139-153.

Golam, K., Sahadat, H. \& Mohammad, S. K. (2014). Influence of Soil Reinforcement on horizontal displacement of MSE wall. International Journal of Geomechanics, 14, No. 1, 130-141.

Han, J. (2015). Principles and Practice of Ground Improvement, John Wiley \& Sons, Hoboken, NJ, USA.

Han, J. \& Leshchinsky, D. (2004). Limit equilibrium and continuum mechanics-based numerical methods for analyzing stability of MSE walls. Proc., 17th ASCE Engineering Mechanics Conf., $A S C E$, Reston, VA, ASCE, University of Delaware, Newark, DE, USA, June 13-16.

Hatami, K. \& Bathurst, R. J. (2005). Development and verification of a numerical model for the analysis of geosynthetic-reinforced soil segmental walls under working stress conditions. Canadian Geotechnical Journal, 42, No. 4, 1066-1085.

Hatami, K. \& Bathurst, R. (2006). Numerical model for reinforced soil segmental walls under surcharge loading. Journal of Geotechnical and Geoenvironmental Engineering, 132, No. 6, 673-684.

Hegde, A. \& Sitharam, T. G. (2015). 3-Dimensional numerical modelling of geocell reinforced sand beds. Geotextiles and Geomembranes, 43, No. 2, 171-181

Ho, S. K. \& Rowe, R. K. (1994). Predicted behavior of two centrifugal model soil walls. Journal of Geotechnical Engineering, 120, No. 10, 1845-1873.

Horpibulsuk, S. \& Niramitkornburee, A. (2010). Pullout resistance of bearing reinforcement embedded in sand. Soils Found, 50, No. 2, 215-226.

Horpibulsuk, S., Suksiripattanapong, C., Niramitkornburee, A., Chinkulkijniwat, A. \& Tangsutthinon, T. (2011). Performance of an earth wall stabilized with bearing reinforcements. Geotextiles and Geomembranes, 29, No. 5, 514-524.

Huang, B., Bathurst, R. \& Hatami, K. (2009). Numerical study of reinforced soil segmental walls using three different constitutive soil models. Journal of Geotechnical and Geoenvironmental Engineering, 135, No. 10, 1486-1498.

Jaky, J. (1944). The coefficient of earth pressure at rest. Journal of the Society of Hungarian Architects and Engineers, 7, No. 4, 355-358.

Keller, G. R. (1995). Experiences with mechanically stabilized structures and native soil backfill. Transportation Research Record, 1474, No. 1474, 30-38.

Kezdi, A. (1974). Handbook of Soil Mechanics, Elsevier, Amsterdam, the Netherlands.

Khedkar, M. S. \& Mandal, J. N. (2009). Pullout behaviour of cellular reinforcements. Geotextiles and Geomembranes, 27, No. 4, 262-271.

Kim, D., Sagong, M. \& Lee, Y. (2005). Effects of fine aggregate content on the mechanical properties of the compacted decomposed granitic soils. Construction and Building Materials, 19, No. 3, 189-196.

Leshchinsky, D., Vahedifard, F. \& Leshchinsky, B. A. (2012). Revisiting bearing capacity analysis of MSE walls. Geotextiles and Geomembranes, 34, 100-107. 
Miyata, Y., Bathurst, R. J. \& Konami, T. (2011). Evaluation of two anchor plate capacity models for MAW systems. Soils and Foundations, 51, No. 5, 885-895.

Mohamed, S. B. A., Yang, K. H. \& Hung, W. Y. (2014). Finite element analyses of two-tier geosynthetic-reinforced soil walls: comparison involving centrifuge tests and limit equilibrium results. Computers and Geotechnics, 61, 67-84.

Naeini, S. A. \& Gholampoor, N. (2014). Cyclic behaviour of dry silty sand reinforced with a geotextile. Geotextiles and Geomembranes, 42, No. 6, 611-619.

Reddy, D. V. \& Navarrete, F. (2008). Experimental and analytical investigation of Geogrid MSE walls. From Research to Practice in Geotechnical Engineering (James E. L., David K. C. and Mohamad H. H. (ed.)). ASCE, New Orleans, LA, USA, March 9-12, pp. 277-291.

Riccio, M., Ehrlich, M. \& Dias, D. (2014). Field monitoring and analyses of the response of a block-faced geogrid wall using fine-grained tropical soils. Geotextiles and Geomembranes, 42, No. 2, 127-138.

Rowe, R. \& Ho, S. (1997). Continuous panel reinforced soil walls on rigid foundations. Journal of Geotechnical and Geoenvironmental Engineering, 123, No. 10, 912-920.

Rowe, R. K. \& Ho, S. K. (1998). Horizontal deformation in reinforced soil walls. Canadian Geotechnical Journal, 35, No. 2, 312-327.

Rowe, R. K. \& Skinner, G. D. (2001). Numerical analysis of geosynthetic reinforced retaining wall constructed on a layered soil foundation. Geotextiles and Geomembranes, 19, No. 7, 387-412.

Sukmak, K., Sukmak, P., Horpibulsuk, S., Han, J., Shen, S. L. \& Arulrajah, A. (2015). Effect of fine content on the pullout resistance mechanism of bearing reinforcement embedded in cohesivefrictional soils. Geotextiles and Geomembranes, 43, No. 2, 107-117.
Sukmak, K., Sukmak, P., Horpibulsuk, S., Chinkulkijniwat, A., Arulrajah, A. \& Shen, S. L. (2016). Pullout resistance of bearing reinforcement embedded in marginal lateritic soil at molding water contents. Geotextiles and Geomembranes, 44, No. 3, 475-483.

Suksiripattanapong, C., Chinkulkijniwat, A., Horpibulsuk, S., Rujikiatkamjorn, C. \& Tanhsutthinon, T. (2012). Numerical analysis of bearing reinforcement earth (BRE) wall. Geotextiles and Geomembranes, 32, 28-37.

Suksiripattanapong, C., Horpibulsuk, S., Chinkulkijniwat, A. \& Chai, J. C. (2013). Pullout resistance of bearing reinforcement embedded in coarse-grained soils. Geotextiles and Geomembranes, 36, 44-54.

Suksiripattanapong, C., Suksun, H., Chinkulkijniwat, A., Chai, J., Shen, S. L., Arulrajah, A. \& Suddeepong, A. (2016). Numerical and sensitivity analysis of bearing reinfoecement earth (BRE) wall. KSCE Journal of Civil Engineering, http://dx.doi.org/10.1007/ s12205-016-0576-4.

Vermeer, P. A. \& Brinkgreve, R. B. J. (1995). Finite Element Code for Soil and Rock Analysis, A.A. Balkema, Rotterdam, the Netherlands.

Wang, Z., Jacobs, F. \& Ziegler, M. (2014). Visualization of load transfer behaviour between geogrid and sand using PFC2D. Geotextiles and Geomembranes, 42, No. 2, 83-90.

Youwai, S. \& Bergado, D. T. (2004). Numerical analysis of reinforced wall using rubber tire chips-sand mixtures as backfill material. Computers and Geotechnics, 31, No. 2, 103-114.

Yu, Y. \& Bathurst, R. (2015). Analysis of soil-steel bar mat pullout models using a statistical approach. Journal of Geotechnical and Geoenvironmental Engineering, 141, No. 5, 04015006.

Yu, Y., Bathurst, R. J. \& Miyata, Y. (2015). Numerical analysis of a mechanically stabilized earth wall reinforced with steel strips. Soils and Foundations, 55, No. 3, 536-547. 